\title{
Location choice with longitudinal WiFi data
}

\author{
Antonin Danalet * \\ Loïc Tinguely * Matthieu de Lapparent *
Michel Bierlaire *
}

11th April 2016

\begin{abstract}
Location-aware data collection technologies provide new insights about location choices. Only a few dynamic models of location choice exist in scientific literature. To our knowledge, none of them correct for serial correlation. In this paper, we model choice of catering locations on a campus using WiFi traces. We use the Wooldridge (2005) correction method that deals with the initial values problem and related endogeneity bias in estimation. Cross-validation, price elasticity and simulation of a scenario predicting the opening of a new catering location are presented. Predicted market shares of the new catering location correspond to point-of-sale data of the first week of opening.
\end{abstract}

\section{Key words}

location choice; panel data; pedestrians; dynamic model; initial conditions problem

\section{Introduction}

Properly modeling destination choices is important in order to understand travel behavior and travel demand, both at the urban scale and in pedestrian facilities. In transportation, destination choice modeling is often used by local and national authorities for planning future infrastructures and policies (e.g., Fox et al. 2014) and for the planning and design of multimodal transport hubs (Hoogendoorn and Bovy; 2004). In tourism, the choice of destinations is important for analyzing demand for holidays locations (e.g., Yang et al.; 2013) and for the management of pedestrian flows in museums (Yoshimura et al.; 2014) and in parks ( $\mathrm{O}^{\prime}$ Connor et al.; 2005). In all of these contexts, destination choice models commonly infer on the relevant factors that influence the decisions and allow the testing of policies when building new infrastructures or optimizing current ones. Demand management strategies can be evaluated.

*ÉCOLE POLYTECHNIQUE FÉDÉRALE DE LAUSANNE (EPFL), School of Architecture, Civil and Environmental Engineering (ENAC), Transport and Mobility Laboratory (TRANSPOR), antonin.danalet@alumni.epfl.ch, loic.tinguely@alumni.epfl.ch, matthieu.delapparent@epfl.ch, michel.bierlaire@epfl.ch 
Most of destination choice models rely on cross-sectional data (e.g., Ben-Akiva and Lerman; 1985; Zhu and Timmermans; 2011; Scott and He; 2012, Kalakou et al.; 2014). As they are collected at one point in time, the related frameworks of analysis are static. As stated by Hsiao (2003), "a longitudinal, or panel, data set is one that follows a given sample of individuals over time, and thus provides multiple observations on each individual in the sample". Panel data are difficult and expensive to collect using standard survey techniques (Yang and Timmermans; 2015), and sometimes nonexistant, e.g., for the analysis of induced traffic at an aggregate level (Weis and Axhausen; 2009). In absence of actual panel data, pseudo-panel data are constructed by grouping individuals from cross sectional data into cohorts and by considering behavior of cohorts as individuals (Deaton; 1985, Weis and Axhausen: 2009, McDonald; 2015). However, actual panel data from new technologies are more and more used (Carrion et al.; 2014; Kazagli et al.; 2014). Network traces (e.g., WiFi traces or cell tower data) are increasingly available for location choices (see Section 2.2). Compared to traditional surveys, network traces follow individuals over longer periods (see Section 2.1). This makes it possible to collect sequences of activity locations covering several days, weeks or months. Location choice models must be adapted to use these data.

In this article, we model dynamics of location choices for catering. We make best use of panel data by taking into account state dependence and serial correlation. We solve the initial values problem and related endogeneity bias in estimation using Wooldridge's (2005) correction method. Accounting for panel data nature in location choices has never been treated in the literature before. It allows us to correct for serial correlation, while understanding people's habits in their decision process. The methodology is applied to sequences of catering locations on a campus collected using WiFi access points (Danalet et al. 2014).

The rest of the paper is organized as follows. Review of literature is presented in Section 2. We detail methodology in Section 3 . Our case study is discussed in Section 4. It also includes cross-validation and forecasting. Conclusions are drawn in Section 5.

\section{Literature review}

\subsection{From diary surveys to location-aware technologies}

One recent trend in travel demand modeling is resorting to location-aware technologies (Chen and Yang; 2014, Danalet et al.; 2014, Miller; 2014, Carrel et al.; 2015). Traditionally, disaggregate data of revealed preferences about activity and travel patterns are collected from diary surveys, where people describe 1 or 2 past days (Ettema; 1996, Carrel et al. 2015). The largest panel surveys include a six-week period for 317 participants (Axhausen et al. 2002), a six-week period for 261 participants (Axhausen et al. 2007) and a twelve-week period for 71 participants (Schlich; 2004). Most long-term surveys cover a maximum of 7 days and are not panel data (Ortúzar et al.; 2011; Carrel et al.; 2015). Location-aware technologies improve the quality of surveying. For instance, combination of GPS devices carried by respondents with standard recall questionnaires makes for easier implementation of longitudinal surveys (Frignani et al. 2010; Yang and Timmermans; 2015). Recall methods can also be directly implemented on mobile devices (Rindfüser et al.: 2003: Cottrill et al.; 2013).

Location-aware technologies can also be used alone. It can be from the communication infrastructure side, such as cell tower traces or WiFi access points traces (Bekhor et al.; 2013; Calabrese et al.; 2013; Danalet et al.; 2014). It can also be from the individuals' devices (Etter et al.; 2012; Buisson; 2014, Chen and Yang; 2014; Carrel et al.; 2015). Etter 
et al. (2012) show that it is possible to predict up to $60 \%$ of next visited places from passive smartphone data.

\subsection{Location choice}

Location choice models are common in studies of urban transportation policies and planning. Ben-Akiva and Lerman (1985) mention three of them, for the Paris region and Maceio, Brazil. Such models have been applied to the choice of location for grocery shopping (Timmermans; 1996; Dellaert et al.; 1998; Fox et al.; 2004; Scott and He; 2012). They also relate to other applications: choice of a departure airport (Furuichi and Koppelman; 1994), the choice of a hospital for patients by general practitioner (primary care physicians) (Whynes et al. 1996), the choice of tourist destinations (Woodside and Lysonski; 1989, Um and Crompton; 1990; Eymann and Ronning; 1997; Oppermann; 2000; Seddighi and Theocharous; 2002; Bigano et al.; 2006; Chi and Qu; 2008; Gössling et al.; 2012; Yang et al.; 2013) and in particular recreational outdoor facilities (Fesenmaier: 1988, Scarpa and Thiene; 2005; Thiene and Scarpa; 2009), the choice of migrants (Fotheringham: 1986) and the optimal allocation of charging stations for electric vehicles (He et al. 2013).

Regarding pedestrians, Zhu and Timmermans (2011) propose heuristic rules pertaining to bounded rationality. They compare them with random utility maximization discrete choice models. The models are validated on the same sample used for estimation. Cross validation is not carried out. Ton (2014) studies route and location choice in train stations based on tracking and counting data. Counting data come from infrared scanners and tracking data come from WiFi and Bluetooth scanners. Count data are used to model pedestrians without smartphones. The choice is between locations for a given activity type, e.g., which coffee shop knowing that the individual is visiting one. Kalakou et al. (2014) apply a similar approach for location choice for a given activity type in an airport.

\subsubsection{Attributes of the choice of a location}

The main attributes in location choices in urban context are travel time, travel cost and distance (Cambridge Systematics Europe; 1984; Ben-Akiva and Lerman; 1985; Whynes et al. 1996). Other variables are used: park-finding time, parking cost, type of neighborhood, and the number of different services (banks, post offices, medical facilities, offices, shops, etc.) in the zone (Cambridge Systematics Europe; 1984; Ben-Akiva and Lerman; 1985). Another typical attribute is the size in the context of aggregation of alternatives (see Section 2.2.2). It represents the number of elemental alternatives in the considered aggregate alternatives (subsets of the choice set). The interpretation of this attribute is complicated, since it absorbs both the preference for a large set of destinations compared to a small one and the correlation between destinations in the set. The expected sign is opposite in the two situations (Frejinger and Bierlaire; 2007). In shop patronage, the main attributes are the retail floor space, the accessibility and the price (Arnold et al. 1983 Scott and $\mathrm{He}$;2012). Other attributes include parking facilities, number of speciality stores, number of retail employees, access to different services (foodcourts, cinemas) (Zhu et al. 2006; Shobeirinejad et al. 2013) or symbolic acts (support of community charities, front-door greeters, patriotic displays) (Arnold et al. 1996).

In the pedestrian context, the main attributes of location choice are the attraction of the location and travel time. More specifically, models include floor space (Borgers and Timmermans; 1986), pedestrian environment in the neighborhood, employment (Eash; 1999) as measures of attractiveness and distance as an approximation of travel time (Borgers 
and Timmermans; 1986, Ton; 2014). Kalakou et al. (2014) include space syntax in the specification of the utility through "integration", i.e., a synthetic measure of accessibility.

\subsubsection{Location choice models}

In an urban context, models are often based on tours, characterized by a travel mode and a destination. Models of joint choice of travel mode and destination often aggregate destinations into zones (Cambridge Systematics Europe; 1984; Ben-Akiva and Lerman; 1985). Stratified importance sampling is used, dividing the destination choice set into nonoverlapping strata based on the origin zone. In the Paris Region example, this procedure decreases the choice set from 595 destinations $\times 4$ travel modes to 7 sampled alternatives for each trip (Cambridge Systematics Europe; 1984; Ben-Akiva and Lerman; 1985). In a pedestrian context, the choice set is often smaller, due to the smaller study area (e.g., Ton; 2014 Kalakou et al.; 2014, with 2 to 4 alternatives). Most destination choice models are logit models (Arnold et al.; 1983 , Zhu et al.; 2006; Scott and He; 2012, Kalakou et al.; 2014: Ton, 2014). Probit models have also been used (e.g., Whynes et al.; 1996).

Panel data have been used for a long time in transportation research (Golob et al. 1997). Habits are often observed in travel behavior (Gärling and Axhausen; 2003), in particular in route choice (Aarts and Dijksterhuis; 2000; Bamberg et al.; 2003; Thøgersen; 2006; Eriksson et al.; 2008; Verplanken et al.; 2008; Gardner; 2009; Schwanen et al.; 2012) and in car ownership (Jong et al.; 2004).

Stopher and Greaves (2007) however mention that panel surveys "have not been embraced by the transport profession. (...) Perhaps the most important reason behind this is that no one is quite sure how to use panel data in modelling". It is especially the case when dealing with modeling of discrete data. For example, in Markov models of destination choices, transition matrix represents the probability of choosing a destination given the choice of destination at the previous stop. Markov models are criticized for being descriptive, replicating the data, and not being sensitive to behavioral changes (Kitamura; 1990; Timmermans et al.; 1992). Yang et al. (2013) model the choice of a second tourist destination after visiting a first one. They use a nested logit. The panel nature of the data is not explicitly taken into account in their model (as in $\mathrm{Wu} ; 2012$, ch. 5.2). The characteristics of the previous destination are not included in their model. McFadden (2001) and Carrel et al. (2015) highlight the importance of panel data in discrete choice models.

Dynamic models using panel data increase statistical efficiency, improve predictions and allow the study of behavioral dynamics (Kitamura; 1990). Kitamura (1990) considers the inclusion of lag terms in discrete choice models not well advanced. Unresolved issues in the estimation of dynamic models using panel data include the representation of the initial conditions and the correlated error term in dynamic models. Few authors explicitly include lagged variables in location models. For non-work activity location choice, Sivakumar and Bhat (2007) include the previous location choices of the individual and the frequency of past visits in the same location in the utility. They do not deal with endogeneity issues due to the presence of lagged utility functions and assume the first location choice to be exogenous. In tourism literature, Grigolon et al. (2014) include the previous vacation length choice in the choice of the current vacation length. They compare a logit, a mixed logit and a dynamic mixed logit and show that the dynamic mixed logit is the best in estimation and forecasting. In their dynamic mixed logit, by assuming that the error term is independent of the variables (i.e., exogenous), and in particular independent of the lagged variable, they assume that unobserved attributes do not persist over time for a given individual. This can lead to bias in the estimation of the model, in particular when the choice of the vacation length of a stay is influenced by variables not included in their 
model. In the choice of a shop in a pedestrian street, Zhu et al. (2006) also face serial correlation and mention independence issues as a technical challenge for future research.

Regarding pedestrian destination choice models, Timmermans et al. (1992) mention in their review the "issue of whether a pedestrian tends to always buy certain items in the same store", i.e., the question of loyalty, as future research.

In light of the above literature review, we emphasize that location-aware technologies allow the collection of useful panel data over long periods. These data must be used in location choice models. Attention must be paid when modeling state dependence (lagged dependent variable). Serial correlation must also be accounted for. State dependence and serial correlation yield bias in estimation if they are not properly taken into account.

Our contribution is to develop a state-of-the-art location choice model using panel data from localization-aware technologies. We consider state dependence and serial correlation. We use Wooldridge (2005) correction method (see Section 3 for details) to correct bias in estimation that is due to endogeneity of the lagged dependent variable. As pointed out by (Arulampalam and Stewart; 2009), Wooldridge (2005) correction method is mostly applied to binary probit. We use it here with a logit model and a choice set that contains 21 alternatives. To our knowledge, this is the first time it is applied in such a context.

\section{Methodology}

We assume that panel data are available and provide observations of location choices over time. An individual $n$ repeatedly visits locations. For each individual $n$, we assume a sequence of events $\left\{1, \ldots, t_{n}, \ldots, T_{n}\right\}$. This sequence is exogenous and individual specific. At each event, a location choice is made. The indicator $y_{i n t_{n}}$ is 1 if individual $n$ selects location $i$ for event $t_{n}$. The time interval between two events vary, as well as the number $T_{n}$ of events per individual. To make the notation light, we use $t$ instead of $t_{n}$ in the following developments.

A sequence of events with varying time intervals between the decisions is typical for the choice of buying or selling for investors in the stock market (e.g., Robin and Bierlaire; 2012). It is also common when considering the activity location choice conditional on an activity type (e.g., Kalakou et al.; 2014, Ton, 2014). The modeling and forecasting of choices of activity type and time intervals between events is covered in Danalet and Bierlaire (2015).

We use a logit model for the choice of a location $i$. We present three models: a static model, a dynamic model without agent effect and a dynamic model with agent effect.

We associate a utility $U_{\text {int }}$ with a location $i$ :

$$
U_{\text {int }}=V_{\text {int }}+\varepsilon_{\text {int }}
$$

where $i \in \mathcal{C}_{n t}$ and $\mathcal{C}_{n t}$ is the choice set of all available locations at time $t$ for individual $n$. This model is simple to estimate when we assume that $\varepsilon_{\text {int }} \stackrel{\text { iid }}{\sim} E V(0,1)$ across $i, n$ and $t$, i.e., a static logit model. It ignores two aspects: dynamics and serial correlation.

First, the choice at a certain event $t$ may depend on previous choices. Individuals have state dependence to already visited locations. For the purpose of simplification, we make three additional assumptions. First, we assume a dynamic process of order one: the current level of utility of location $i$ partly depends on the previously chosen location for the same type of activity. Second, the state dependence is location specific: utility for a location only depends on previous choice of this location. Third, we assume that the weight $\rho$ of this state dependence is the same for every individual $n$ and every location $i$ (the assumption 
could be relaxed by considering variations across locations and individuals):

$$
U_{i n t}=V_{i n t}+\rho y_{i n(t-1)}+\varepsilon_{i n t}
$$

where $y_{i n(t-1)}$ is a dummy variable with value one if location $i$ was chosen by individual $n$ as the previous location choice, and 0 otherwise. The coefficient $\rho$ measures the effect of previous experience of the location on its current utility. $\rho$ can be specific to the time of day, e.g., the choice of a catering location for a coffee break in the afternoon depends on the previous catering location choice in the afternoon, ignoring the other catering activity locations in-between.

We assume that the time interval between two events does not change the impact of the previous experience, i.e., the duration between two events does not affect the choice probability. The choice probability of an activity location is only influenced by a previous visit at the same activity location. There is no memory fading.

We initially assume that the previous choice $y_{i n(t-1)}$ is independent of the error term $\varepsilon_{\text {int }}$ (strict exogeneity assumption) and that $\varepsilon_{\text {int }}$ are independent and identically distributed across $i, n$ and $t$. We term such a model a dynamic model without agent effect.

The error terms $\varepsilon_{\text {int }}$ model the unobserved factors. In the static and the dynamic model without agent effect, we assume that they are independently distributed over time, individuals and locations. In practice, it is very likely that they share time-invariant components associated with the decision-maker, thereby generating serial correlation. This raises the second issue of the static model. For example, in the successive choice of a restaurant, a preference for healthy food is usually unobserved (Burton et al.; 2014; Chen and Yang; 2014). In our context, it can be considered as an unobserved time-invariant factorl]

As a consequence, the lagged variable $y_{i n(t-1)}$ and the unobserved factors $\varepsilon_{i n t}$ are correlated since they both depend on the time-invariant factor, also known as agent effects. This is called endogeneity. It has to be taken into account to avoid bias in the estimation of the parameters of the model.

We relax the independence assumption of error terms $\varepsilon_{i n(t-1)}$ and $\varepsilon_{i n t}$ by replacing the original single error term $\varepsilon_{i n t}$ by the sum of two error terms: $\alpha_{i n}+\varepsilon_{i n t}^{\prime} . \alpha_{i n}$ is the agent effect. It is time-invariant and represents the long-term preferences of individual $n$ over time for location $i$. The agent effect $\alpha_{i n}$ does not vary over time but varies across individuals (inter-individual variability). $\varepsilon_{\text {int }}^{\prime}$ is the unobserved heterogeneity and represents the short-term variation of preferences of individual $n$ (intra-individual variability). $\varepsilon_{\text {int }}^{\prime}$ are independent across time and individuals. The utility function becomes:

$$
U_{i n t}=V_{i n t}+\rho y_{i n(t-1)}+\alpha_{i n}+\varepsilon_{i n t}^{\prime} .
$$

As stated by Wooldridge (2005), accounting for endogeneity in estimation of panel data models with agent effects and lagged dependent variables requires the computation of the marginal/steady state choice probability for the first observed outcome of the dependent variable. This is often referred as the initial conditions problem in econometrics (Heckman: 1981; Hsiao, 2003, Train, 2003, Wooldridge; 2005). Computation of such marginal probability is intractable except for some simple binary models (see Bhargava and Sargan; 1983. Hsiao, 2003 (Section 4.3) and Wooldridge; 2005). Several authors have proposed circumventing strategies to solve this problem (see Hsiao, 2003 and Wooldridge, 2005 for reviews). We build here on the Wooldridge (2005) correction method.

\footnotetext{
${ }^{1}$ We agree that taste may change in the lifecycle of an individual, but not during the time horizon of the data we use for the application.
} 


\subsection{Correcting endogeneity for dynamic discrete choice models}

In general, endogeneity must be corrected to get consistent estimates (Train; 2003, Ch. 13). Control functions capture the relationship between the unobserved factors and the observed variables and "absorb" endogeneity (Heckman; 1978).

Wooldridge (2005) proposes to model the distribution of the agent effect $\alpha_{i n}$ conditional on the initial value and any exogenous explanatory variables:

$$
\alpha_{i n}=a+b y_{i n 0}+c^{\prime} \bar{x}_{n}+\xi_{i n}
$$

where $\xi_{\text {in }}$ is normally distributed, $\xi_{\text {in }} \sim N\left(0, \Sigma_{\alpha}\right)$, with $\Sigma_{\alpha}$ is a matrix of parameters to be estimated ${ }^{2}$, and $\bar{x}_{n}$ is a vector of time-invariant explanatory variables (i.e., long-term preferences, socioeconomic characteristics). The utility of the dynamic model with agent effect is:

$$
U_{i n t}=V_{i n t}+\rho y_{i n(t-1)}+a+b y_{i n 0}+c^{\prime} \bar{x}_{n}+\xi_{i n}+\varepsilon_{i n t}^{\prime} .
$$

The endogeneity issue is addressed with this utility function, given the assumption in Eq. 4 is valid (see Wooldridge (2005) for a detailed discussion). The contribution of a series of observations $y_{\text {int }}$ at times $t=1, \ldots, T$ for individual $n$ to the likelihood function, conditional on the initial value $y_{i n 0}$ and the agent effects $\alpha_{n}=\left\{\alpha_{i n}, \forall i\right\}$, is:

$$
P\left(y_{i n 1}, y_{i n 2}, \ldots, y_{i n t} \mid y_{i n 0}, \alpha_{n}\right)=\prod_{t=1}^{T} P\left(y_{i n t} \mid y_{i n 0}, y_{i n(t-1)}, \alpha_{n}\right) .
$$

Note that we do not model the first choice $y_{i n 0}$. Given our assumptions, it turns out that our estimator is a conditional maximum likelihood estimator. It is asymptotically equivalent to the full information maximum likelihood estimator. Only efficiency is affected.

When integrating out the agent effects $\alpha_{n} \in \mathbb{R}^{\operatorname{dim}(i)}$, as for any mixture model, Eq. 6 becomes:

$$
P\left(y_{i n 1}, y_{i n 2}, \ldots, y_{i n t} \mid y_{i n 0}\right)=\int_{\alpha_{n}} \prod_{t=1}^{T} P\left(y_{i n t} \mid y_{i n 0}, y_{i n(t-1)}, \alpha_{n}\right) f\left(\alpha_{n} \mid y_{i n 0}, \bar{x}_{n}\right) d \alpha_{n} .
$$

Here, $P\left(y_{i n t} \mid y_{i n 0}, y_{i n(t-1)}, \alpha_{n}\right)$ is a logit model. $f\left(\alpha_{n} \mid y_{i n 0}, \bar{x}_{n}\right)$ is normally distributed, following Eq. 4. Endogeneity is corrected.

Table 1 summarizes the three different models presented in Section 3.

\begin{tabular}{ccc}
\hline Static model & $\begin{array}{c}\text { Dynamic model } \\
\text { without agent effect }\end{array}$ & $\begin{array}{c}\text { Dynamic model } \\
\text { with agent effect }\end{array}$ \\
\hline$\rho=0$ & $\rho \neq 0$ & $\rho \neq 0$ \\
$a, b, c, \sigma_{\alpha}^{2}=0$ & $a, b, c, \sigma_{\alpha}^{2}=0$ & $a, b, c, \sigma_{\alpha}^{2} \neq 0$ \\
\hline
\end{tabular}

Table 1: Description of static model, dynamic model without agent effect and dynamic model with panel effect as a function of $\mathrm{Eq} 5$.

\footnotetext{
${ }^{2}$ Note that Wooldridge (2005) is more general in his approach and other distributions might be used. Here we assume $\Sigma_{\alpha_{i}}=\sigma_{\alpha_{i}}^{2} I$. In the current developments, the parameters of the normal distribution $\sigma_{\alpha_{i}}$ are location specific, but the $i$ subscript is omitted to make the notation light.
} 


\section{Pedestrian case study for EPFL catering locations}

We present results for the three models described in Section 3, summarized in Table 1 , in the context of location choice on the EPFL campus. We focus on the choice of catering facilities during their opening hours. The choice set $\mathcal{C}$ contains 21 alternatives corresponding to the services available in 2012 (Figure 1).

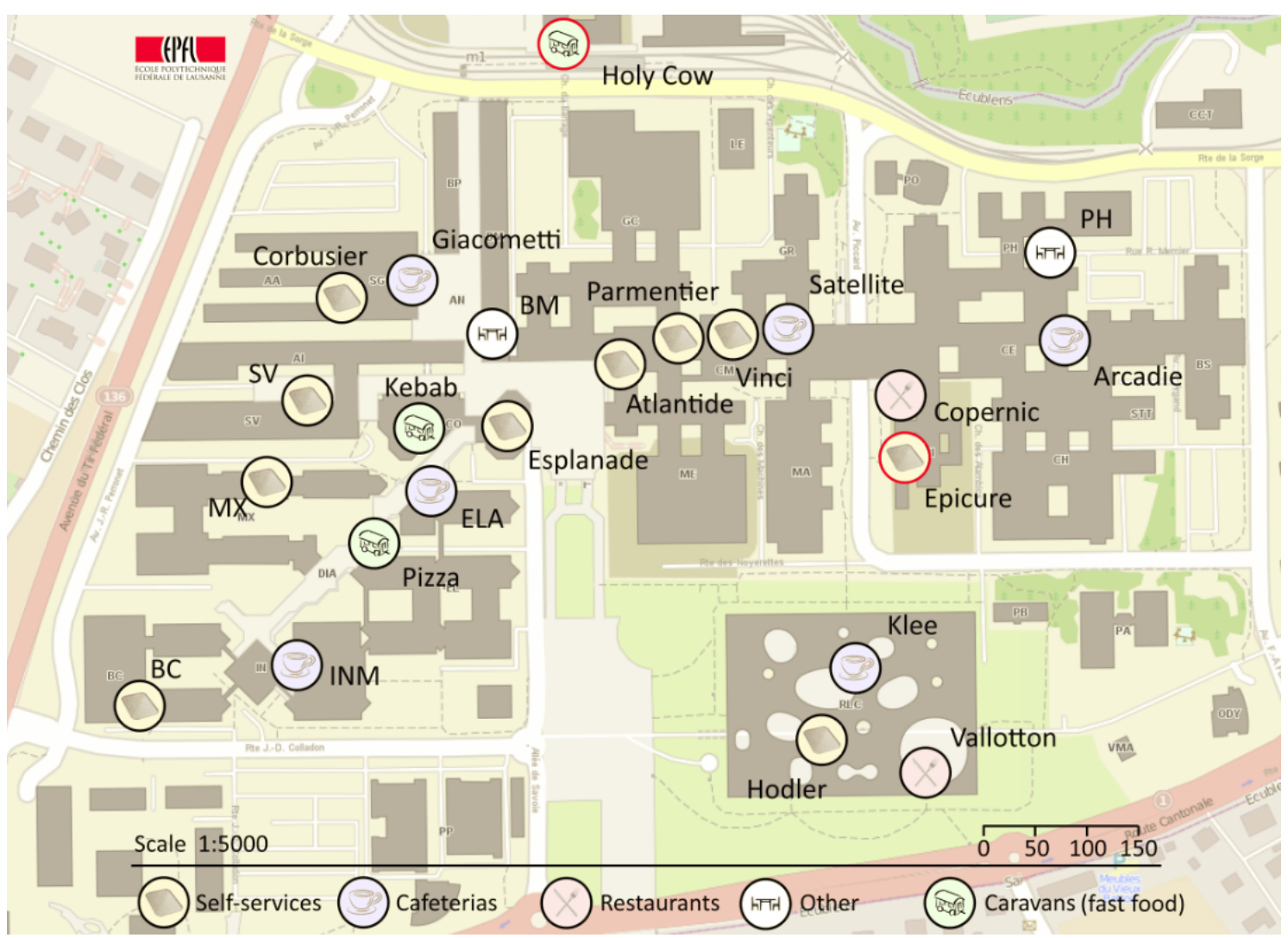

Figure 1: Catering facilities on EPFL campus with different categories: self-services, cafeterias, restaurants, caravans (fast food) and others. The alternatives in red circles did not exist in 2012, when WiFi traces were collected. Image: Tinguely (2015).

Section 4.1 presents the WiFi data collection process. Section 4.2 describes the model specification and the estimation results. Based on this model, validation, elasticity to price and forecasts in the case of the opening of a new catering location can be found in Section 4.3 , 4.4 and 4.5 respectively.

The processed data, the model specification files for Pythonbiogeme (Bierlaire; 2003 , Bierlaire and Fetiarison, 2009) and the results are available as additional material.

\subsection{Data collection and processing}

\subsubsection{Raw WiFi traces}

We use WiFi traces to detect sequences of activity episodes. Campus employees and students have to authenticate themselves on the WiFi network through WPA using a RADIUS server. The RADIUS server provides authentification, authorization and accounting for users who connect and use the WiFi network. Accounting allows to associate a MAC address (identification of the device) with a username (identification of the user). Each 
measurement is associated with a unique identifier and a professional category, such as employee or civil engineering student, bachelor. Data are then anonymized by deleting the MAC address and the username. Here, a measurement corresponds to a localization and a timestamp, associated with an individual, represented by an anonymous unique identifier and a professional category. More than 2 million measurements were collected in Spring 2012, corresponding to 5902 unique identifiers (4140 employees, 1033 EPFL students and 729 other students). Details about the data collection campaign and data cleaning can be found in Appendix A.2 in Danalet (2015b) and raw data are available in Danalet (2015a).

\subsubsection{A Bayesian procedure to detect activity-episode sequences}

The Bayesian approach detailed in Danalet et al. (2014) is then applied to the cleaned WiFi traces in order to detect activity-episode sequences. Activity episodes are defined as an episode location (a point of interest), an episode start time and an episode end time. WiFi traces are merged with map information (localization of points of interest and length of the shortest path between two points) and a potential attractivity measure. The potential attractivity measure is an aggregate measure of occupancy. It provides the expected number of people in each point of interest from other data sources than WiFi traces, e.g., from point-of-sale data, cumulative work percentage of the employees per office, registered students per class, number of seats of the library. Time constraints (e.g., shop opening or class schedules) are also included in the potential attractivity measure. The potential attractivity measure is used as a prior in the Bayesian procedure. This Bayesian approach detects stops and gives semantics to the WiFi traces. It generates a list of candidate activity-episode sequences for each series of measurements and each individual, with their probability of being the true one. Here, we keep only the most likely activityepisode sequence for each day of measurements, per person (it corresponds to $L=1$ in Danalet et al.; 2014). A precise definition of the data used for defining the potential attractivity measure can be found in Appendix A.2 in Danalet (2015b). Map data and data sources for the potential attractivity measure are available in Danalet (2015a).

\subsubsection{The catering location choice data}

For each activity-episode sequence, we keep the activity episodes corresponding to a catering location during the opening hours. The activity episode preceding a visit to a catering destination is used to compute the distance walked by the individual to reach the catering location. We end up with 1868 observations performed by 211 members of campus (649 observations by 66 EPFL students and 1219 observations by 145 employees). Descriptive statistics on the catering activity episodes show that individuals' choices are influenced by distance from the previous activity episode localization and habits (Tinguely; 2015). The catering location choice data are available as additional material.

\subsection{Model specification and estimation}

The explanatory variables used for the location choice are: (1) alternative specific attributes: distance from the previous activity location in the sequence, duration, cost, time of the day, opening hours, quality evaluation of the catering location, its capacity, its type of offer; (2) characteristics describing the choice context, constant across alternatives: weather conditions, day of the year, socio-economic attributes. Descriptive statistics on the collected data are available in Appendix A.1.

In the dynamic models, habits are assumed only for the morning and lunch break. Two lagged variables $y_{i n(t-1)}$ are defined in the dynamic models, one for the morning and one 
for the lunch break. Thus, the dynamic Markov process is over individuals and periods of the day. Equations 2 and 3 become:

$$
\begin{aligned}
& U_{i n t}=V_{i n t}+\rho_{\text {morning }} y_{i n(t-1)}^{\text {morning }}+\rho_{\text {lunch }} y_{i n(t-1)}^{\text {lunch }}+\varepsilon_{i n t} \\
& U_{i n t}=V_{i n t}+\rho_{\text {morning }} y_{i n(t-1)}^{\text {morning }}+\rho_{\text {lunch }} y_{i n(t-1)}^{\text {lunch }}+\alpha_{i n}^{\text {morning }}+\alpha_{i n}^{\text {lunch }}+\varepsilon_{i n t}^{\prime}
\end{aligned}
$$

The specification of the agent effect distribution must be correct to get consistent estimates (Wooldridge; 2005). We propose two different specifications for the agent effect $\alpha_{i n}$. The first specification corresponds to $c=0$ in Eq. 4. We assume the agent effect to depend only on the first choice:

$$
\alpha_{i n}=a+b y_{i n 0}+\xi_{n}
$$

The second specification for the agent effect includes the count $y_{\text {int }}^{\text {count }}$ of previous choices of alternative $i$ by individual $n$ up to the event $t$ of the current choice: $y_{\text {int }}^{\text {count }}=$ $\sum_{t^{\prime}=1}^{t-1} I\left(y_{i n t^{\prime}}\right)$. Note that in the definition of the count of previous choices, the first observation $y_{i n 0}$ is not included and the summation start at $t^{\prime}=1$. It allows to avoid biases (Rabe-Hesketh and Skrondal; 2013).

Eq. 4 becomes:

$$
\alpha_{i n}=a+b y_{i n 0}+c y_{\text {int }}^{\text {count }}+\xi_{n} .
$$

Since the lagged variable $y_{i n(t-1)}$ is interacted with the period of the day, the count of previous choices is also specified for each period of the day.

Consequently, we estimate 4 models: the static model (utility defined in Eq. 1), a dynamic model without agent effect (utility defined in Eq. 2) and two dynamic models with agent effect: one with a first choice agent effect specification (Eq. 10) and one with a first choice and frequency specification (Eq. 11).

\begin{tabular}{cccc}
\hline Static model & $\begin{array}{c}\text { Dynamic model } \\
\text { without agent effect }\end{array}$ & \multicolumn{2}{c}{$\begin{array}{c}\text { Dynamic model } \\
\text { with agent effect }\end{array}$} \\
\hline$\rho=0$ & $\rho \neq 0$ & $\rho \neq 0$ & $\rho \neq 0$ \\
$a=0$ & $a=0$ & $a \neq 0$ & $a \neq 0$ \\
$b=0$ & $b=0$ & $b \neq 0$ & $b \neq 0$ \\
$c=0$ & $c=0$ & $c=0$ & $c \neq 0$ \\
$\sigma_{\alpha}^{2}=0$ & $\sigma_{\alpha}^{2}=0$ & $\sigma_{\alpha}^{2} \neq 0$ & $\sigma_{\alpha}^{2} \neq 0$ \\
\hline
\end{tabular}

Table 2: Description of static model, dynamic model without agent effect and two dynamic models with panel effect used in the case study as a function of $\mathrm{Eq} 5$.

We use a linear specification for the different models, whose variables are described in Table 3. The complete estimation results for the 4 models of Table 2 can be found in Table 7 in Appendix A.2. The main observations from the estimation are described below.

Lagged variables $\rho_{\text {lunch }}$ and $\rho_{\text {morning }}$ have positive signs, showing habits and repeated choices. Their value decreases when the dynamic model includes the agent effect (as compared to the model when it is considered exogenous). It has been reported in Monte Carlo simulations that $\rho$ is overestimated in dynamic models without agent effect as compared to dynamic models with agent effect (Akay, 2012). This is due to the double nature of the lagged variable $\rho$ : the previous choice impacts the current choice because the past experience modifies the current preferences and because the past and current choices both 


\begin{tabular}{|c|c|c|}
\hline Parameters & Variables & Description of the variable \\
\hline$A S C_{i}$ & $1_{i}$ & Alternative specific constant for catering location $i$ \\
\hline$\beta_{\text {dist, cat }, T o D}$ & $\operatorname{dist}_{\text {cat }, T o D}$ & $\begin{array}{l}\text { Distance from the previous activity episode (previous } \\
\text { stop, not necessarily a catering location) }\end{array}$ \\
\hline$\beta_{\text {no dist }}$ & $1_{\text {dist } N A}$ & Variable for missing data about distance \\
\hline$\beta_{\text {eval }}$ & eval $_{i}$ & $\begin{array}{l}\text { Evaluation of catering location from survey data (grade } \\
\text { between } 1 \text { and } 6 \text { ) }\end{array}$ \\
\hline$\beta_{\text {cost, student }}$ & cost $_{\text {students }}$ & Cost of the cheapest meal for students \\
\hline$\beta_{\text {cost, employees }}$ & cost $_{\text {employees }}$ & Cost of the cheapest meal for employees \\
\hline$\beta_{\text {beer }}$ & $1_{\text {beer }}$ & Availability of beer after 14:00 \\
\hline$\beta_{\text {dinner }}$ & $1_{\text {dinner }}$ & Availability of dinner \\
\hline$\beta_{\text {capacity }}$ & capacity $_{\text {outdoor }}$ & Number of seats in the catering location \\
\hline$\rho_{T o D}$ & $y_{i t(t-1), T o D}$ & $\begin{array}{l}\text { Indicator variable with value } 1 \text { if the previous catering } \\
\text { location in the same time of day }(T o D) \text { is the same as } \\
\text { the current catering location }\end{array}$ \\
\hline$c_{T o D}$ & $y_{\text {int }}^{\text {count }}$ & $\begin{array}{l}\text { Variable counting the frequency of visit to catering loc- } \\
\text { ation } i \text { in the same time of day }(T o D)\end{array}$ \\
\hline$\sigma_{i, T o D}$ & $1_{T o D}$ & $\begin{array}{l}\text { Variance of } \xi \text { for each time of day }(T o D) \text { and each } \\
\text { catering location } i\end{array}$ \\
\hline
\end{tabular}

Table 3: Description of the variables in the catering location choice model. Some variables are interacted with the professional category of catering location (cat), i.e. the categories of restaurant presented in Figure 1, or are interacted with time of day $(T o D)$, divided in morning (until 11:29), lunch break (11:30-13:59), afternoon (14:00-17:59), dinner (18:0019:59) and night (from 20:00). 
depend on the same time-persistent unobserved parameters. These two factors are called true state dependence and spurious state dependence, respectively, by Heckman (1978, 1981) (see also Hsiao; 2003 , Section 7.5.4). The agent effect, and in particular the first choice and frequency version of it, absorbs the time-persistent unobserved preferences.

The parameters have expected signs. Indoor capacity (number of seats) has a positive impact on the choice of visiting a catering location. Distance from the previous activity episode has a negative impact on the propensity to visit a catering location. This effect is strong in the morning and during lunchtime for cafeterias. It is not significant in the afternoon and during lunchtime for restaurants. Indeed, there are not many restaurants on campus, and consequently longer distances to walk. The cost parameters have a negative sign and their magnitude is larger for students than for employees. This is explained by the fact that employees have salaries and thus a higher purchasing power and a lower sensitivity to price. Annual evaluations by students (as a proxy for average quality), offering meals for dinner and beers after 14:00 all have a positive impact on the choice of catering locations.

The dynamic model without agent effect, the dynamic model with agent effect (first choice correction) and the dynamic model with agent effect (first choice and frequency correction) are unrestricted versions of the previous, simpler model in Table 2 (i.e., static model, dynamic model without agent effect, dynamic mode with agent effect (first choice correction), resp.). Three likelihood ratio tests have been performed. In all cases, we can reject the null hypothesis at a $95 \%$ confidence level and the unrestricted model is preferred to the restricted one. Numerical results can be found in Table 7 (last line) in Appendix A.2.

\subsection{Validation}

Cross-validation has been performed, partitioning the data in an estimation dataset containing past observations $i_{1}, i_{2}, \ldots, i_{T_{n}-1}$ of individuals $n$ and a validation dataset with their most recent choice $i_{T_{n}}$. Models presented in Section 4.2 are applied to observations in the morning and during lunch break, in order to test the dynamics. The estimation dataset contains 1512 observations. The model is then applied to the validation dataset (containing 144 observations), using the parameter estimates from the previous step. Aggregate average number of visits across individuals' most recent choices from observations and from the model output are compared in Table 4.

In order to compare the performance of the different models over all catering locations in Table 4, we compute the sum of the squares of the errors: $S_{m}=\sum_{i}\left(O_{i}-E_{i, m}\right)^{2}$, where $O_{i}$ is the observed average number of visits for location $i$ and $E_{i, m}$ is the expected average number of visits based on the choice probabilities for location $i$ assuming model $m$.

Observed and predicted average number of visits show similar tendencies, even for the static model, meaning that the specification of the model is generally good. The model minimizing the sum of the squares of the errors is the dynamic model with agent effect using the first choice and the frequency. It is also the model that fits the data the best (Table 7). It is an evidence that Wooldridge's approach is valid, and it performs better when the specification of the agent effect distribution includes the frequency of visits.

\subsection{Elasticity to price}

Aggregate direct elasticity of cost denotes the percent change in the number of visits for each catering location with respect to a change of $1 \%$ in the cost of a meal. Aggregate direct elasticities of cost are presented for each restaurant, for students and employees, in Table 8 in Appendix A.3. Figure 2 summarizes the distribution of aggregate direct elasticities of cost as box-plots for each model, across students and employees. 


\begin{tabular}{|c|c|c|c|c|c|c|c|c|c|c|}
\hline \multirow[b]{4}{*}{ Catering locations } & \multicolumn{2}{|c|}{ Observed } & \multicolumn{8}{|c|}{ Predicted } \\
\hline & \multirow[b]{3}{*}{$\mathrm{Nb}$} & \multirow[b]{3}{*}{$\%$} & \multirow{2}{*}{\multicolumn{2}{|c|}{ Static model }} & \multirow{2}{*}{\multicolumn{2}{|c|}{$\begin{array}{l}\text { Dynamic model } \\
\text { without agent effect }\end{array}$}} & \multicolumn{4}{|c|}{$\begin{array}{l}\text { Dynamic model } \\
\text { with agent effect }\end{array}$} \\
\hline & & & & & & & \multicolumn{2}{|c|}{ First choice } & \multicolumn{2}{|c|}{$\begin{array}{l}\text { First choice } \\
\text { and frequency }\end{array}$} \\
\hline & & & $\mathrm{Nb}$ & $\%$ & $\mathrm{Nb}$ & $\%$ & $\mathrm{Nb}$ & $\%$ & $\mathrm{Nb}$ & $\%$ \\
\hline Cafet. Le Klee & 0 & 0.0 & 0.4 & 0.3 & 0.3 & 0.2 & 0.4 & 0.3 & 0.3 & 0.2 \\
\hline Cafet. ELA & 14 & 9.7 & 7.6 & 5.3 & 6.9 & 4.8 & 8.0 & 5.5 & 8.0 & 5.6 \\
\hline Cafet. INM & 1 & 0.7 & 1.2 & 0.9 & 1.1 & 0.8 & 2.2 & 1.5 & 2.1 & 1.4 \\
\hline Cafet. MX & 6 & 4.2 & 6.3 & 4.4 & 6.4 & 4.4 & 5.3 & 3.7 & 5.8 & 4.0 \\
\hline Cafet. L'Arcadie & 6 & 4.2 & 1.4 & 1.0 & 2.4 & 1.7 & 1.5 & 1.1 & 1.7 & 1.2 \\
\hline Cafet. Le Giacometti & 13 & 9.0 & 12.0 & 8.3 & 11.8 & 8.2 & 12.8 & 8.9 & 12.2 & 8.5 \\
\hline Cafet. Satellite & 5 & 3.5 & 7.2 & 5.0 & 7.6 & 5.3 & 7.8 & 5.4 & 7.5 & 5.2 \\
\hline Self BC & 15 & 10.4 & 9.7 & 6.7 & 9.5 & 6.6 & 10.8 & 7.5 & 10.8 & 7.5 \\
\hline Self L'Atlantide & 7 & 4.9 & 10.8 & 7.5 & 10.6 & 7.4 & 8.2 & 5.7 & 8.1 & 5.6 \\
\hline Self Le Corbusier & 4 & 2.8 & 12.6 & 8.7 & 10.6 & 7.4 & 9.4 & 6.5 & 10.8 & 7.5 \\
\hline Self Le Parmentier & 8 & 5.6 & 13.1 & 9.1 & 12.9 & 9.0 & 13.1 & 9.1 & 13.2 & 9.1 \\
\hline Self Le Vinci & 1 & 0.7 & 0.2 & 0.1 & 0.2 & 0.1 & 0.2 & 0.1 & 0.2 & 0.1 \\
\hline Self L'Esplanade & 23 & 16.0 & 26.1 & 18.2 & 25.9 & 18.0 & 24.2 & 16.8 & 24.4 & 17.0 \\
\hline Self L'Ornithorynque & 15 & 10.4 & 15.0 & 10.4 & 16.4 & 11.4 & 15.6 & 10.8 & 15.7 & 10.9 \\
\hline Self Le Hodler & 6 & 4.2 & 5.2 & 3.6 & 6.1 & 4.3 & 5.7 & 4.0 & 6.2 & 4.3 \\
\hline Rest. Le Copernic & 1 & 0.7 & 1.0 & 0.7 & 1.4 & 1.0 & 3.4 & 2.4 & 3.3 & 2.3 \\
\hline Rest. Table de Vallotton & 1 & 0.7 & 1.3 & 0.9 & 1.1 & 0.8 & 0.6 & 0.4 & 0.5 & 0.3 \\
\hline Caravan Pizza & 6 & 4.2 & 4.2 & 2.9 & 4.5 & 3.1 & 4.5 & 3.1 & 4.8 & 3.4 \\
\hline Caravan Kebab & 5 & 3.5 & 3.6 & 2.5 & 3.7 & 2.6 & 3.5 & 2.4 & 3.8 & 2.6 \\
\hline Other BM & 1 & 0.7 & 1.8 & 1.2 & 1.2 & 0.8 & 1.6 & 1.1 & 1.3 & 0.9 \\
\hline \multirow[t]{2}{*}{ Other PH } & 6 & 4.2 & 3.2 & 2.2 & 3.6 & 2.5 & 3.3 & 2.3 & 3.3 & 2.3 \\
\hline & & & \multicolumn{2}{|c|}{232.95} & \multicolumn{2}{|c|}{204.01} & \multicolumn{2}{|c|}{184.16} & \multicolumn{2}{|c|}{173.85} \\
\hline
\end{tabular}

Table 4: Aggregate average number of visits of the observations and of the different models, from the 144 most recent observations for each individual in the morning and during lunch break. For the observations and for each model, the number of visitors ("Nb") and the proportion of visitors ("\%") are presented for each catering location. "Rest." stands for restaurant, "Self" for self-service, "Cafet." for cafeteria. 


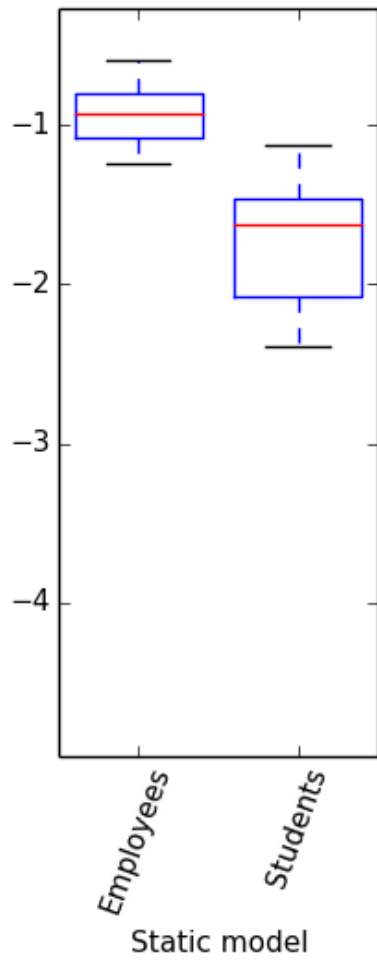

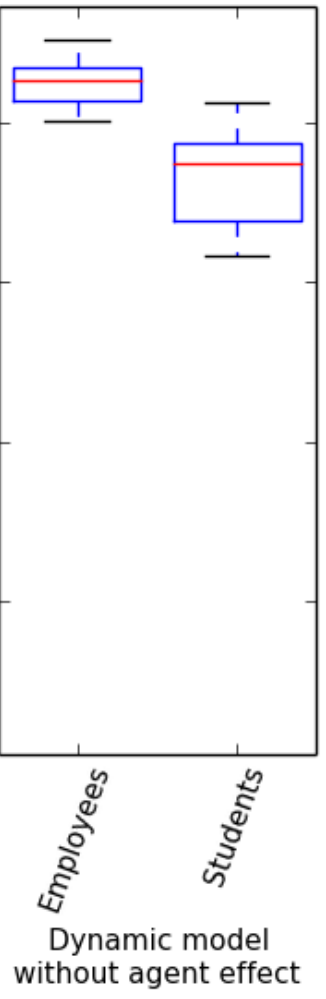

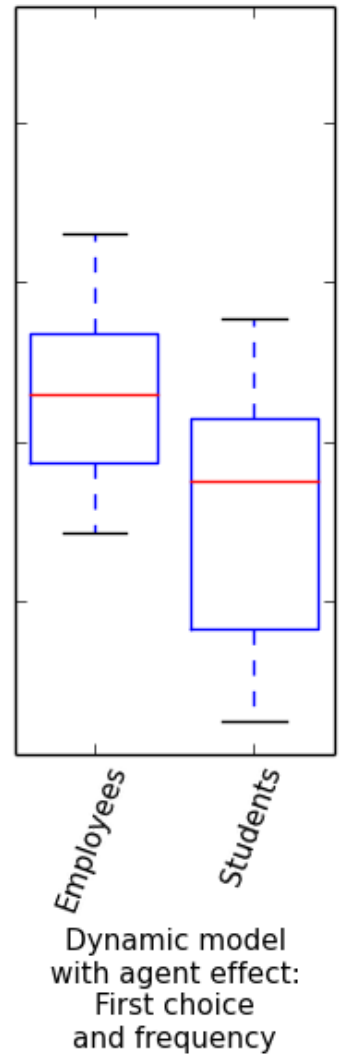

Figure 2: Distribution of aggregate direct elasticities of cost for different models, for students and employees.

Demand for catering locations for students is more elastic to a change in the cost of a meal as compared to employees. This is explained by the higher purchasing power of employees. With the static model and the dynamic model without agent effect, employees mostly show a inelastic demand ( $<1$ in absolute value) and students show an elastic demand ( $>1$ in absolute value). With the dynamic models with agent effect, using the first choice and the frequency of choices, the absolute values of elasticities increase and employees have an elastic demand with respect to the cost of a meal. Generally, models ignoring the dynamics are less sensitive to cost. A possible analogy is the presence of unobserved variables, such as quality of the service or of the meal (Train; 2003, ch. 13). Decision makers prefer cheap meals, but also like quality meals. When endogeneity is not corrected for, $\beta_{\text {cost }}$ absorbs both effects and its absolute value is attenuated. When endogeneity is accounted for, $\beta_{\text {cost }}$ is more negative, including only the taste for cheap meals. Here, in the static model and the model without agent effect, $\beta_{\text {cost }}$ absorbs a taste for cheap meals and other unobserved factors positively correlated with cost, such as a warm atmosphere or any attribute of quality for a meal. In the models with agent effect, unobserved factors are absorbed by the agent effect.

\subsection{Forecasting visits when opening a new catering location}

Data used for estimation were collected in 2012. We forecast the average number of visits for 2013 after the opening of a new self-service.

In this scenario, habits regarding the new catering location are not considered. The 
new alternative is not part of people's habits in the model: the previous catering location and the frequency of visits are null $\left(y_{i n(t-1)}=0\right.$ and $y_{\text {int }}^{\text {count }}=0$ when $i$ is the new catering location).

A new self-service, L'Epicure, opened in October 2013. The four models of Table 2 are applied to this new choice set. The parameters for the new self-service are the same as $L e$ Giacometti, since it is the most similar existing catering location on campus and no stated preference is available.

The error term of the new alternative and the error term of the most similar existing alternative might be correlated. Indeed, if the new catering location does not share any unobserved attribute with the most similar catering location, a logit specification is valid. On the contrary, if unobserved attributes are shared, the two locations should be included in a nest and a nested logit specification is used for forecasting. Since we do not know the value of the nest parameter $\theta$, an interval of values is used from 1 (i.e., logit model and independent error terms) to $+\infty$ (i.e., perfectly correlated error terms) when applying the model to forecast average number of visits. Results are presented in Fig. 3.

When using a static model, the predicted average frequency of visits varies between $0.7 \%$ and $2.0 \%$ for the full day. When correcting for endogeneity and using frequency of visits in the specification of the agent effect, the predicted average frequency of visits varies between $0.4 \%$ and $1.1 \%$. This shows that correcting for endogeneity when using panel data has a significant impact when predicting the destination choices of people. The effect of the unknown level of correlation between the new catering location and its most similar alternative also seems lower when using the dynamic models with agent effect.

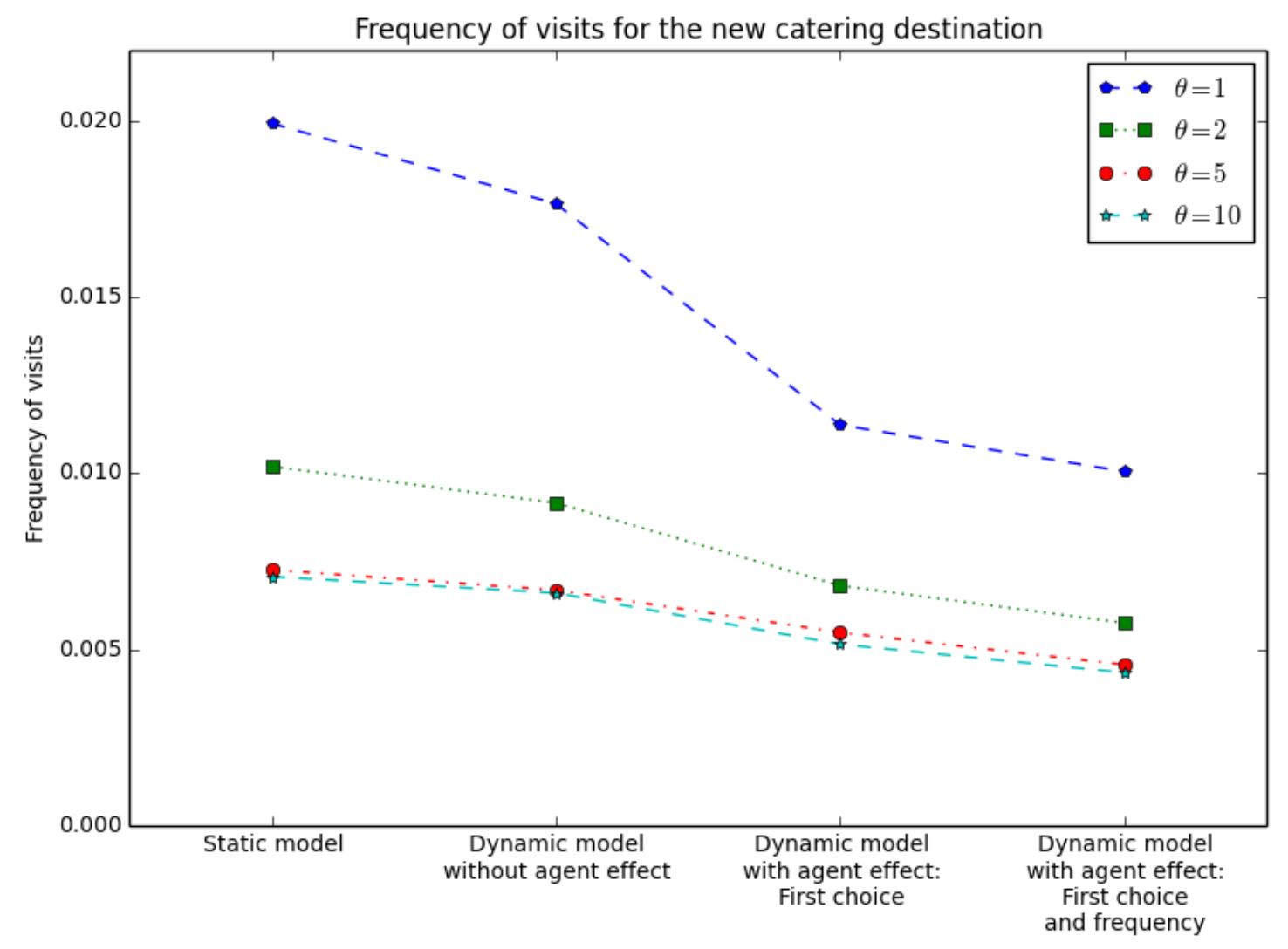

Figure 3: Average frequency of visits for the new self-service for the different models, as a function of $\theta$. 
According to point-of-sale data collected from October 21 to 23, 2013, the frequency of financial transactions in the new self-service is $1.5 \%$, which has a level of magnitude consistent with the values predicted by the model.

Results presented here are only valid in the short term, since the model has been applied only once. For forecasting in the long term, accounting for the habits and routines, the model should be applied several times so that habits for the new location are established as an output of the model.

\section{Conclusion}

In this article, we model location choice conditional on the choice of activity type in activity episodes from WiFi traces. WiFi traces provide panel data. We estimate dynamic models, including lagged variables. They express the habits that could appear in repeated choices.

Including lagged variables in a discrete choice model generates endogeneity. The error term and the explanatory variable representing the previous choice are serially correlated. The so-called initial conditions problem is solved using a control function proposed by Wooldridge (2005). The error term is decomposed in an agent effect and an independent error term. The conditional distribution of the agent effect, knowing the first choice, is approximated.

The approach of Section 3 has been applied to a case study on a campus (Section 4), based on actual WiFi traces, preprocessed as in Danalet et al. (2014). Campus members tend to visit catering locations that are closer, have large capacities, and that offer beer and serve meals at dinner. Students are more sensitive to cost than employees. The previous choice significantly impacts the choice of the current catering location in the morning and in the lunch break in a dynamic model without agent effect, without the correction for endogeneity. When controlling for true state dependence and spurious state dependence, time-persistent unobserved effects are detected and the previous choice becomes no longer significant. A likelihood ratio test has been performed between the different models:

- the static model is rejected when compared to the dynamic model without agent effect

- the dynamic model without agent effect is rejected when compared to the a dynamic model with agent effect

- the model without the frequency of the first choice is rejected when compared to the model with the frequency.

Models are validated in Section 4.3 and the models seem correctly specified, reproducing the observations of the validation dataset. In terms of predictive power, dynamic models outperform static models, and the agent effect including the first choice and the frequency of visits performs the best.

Elasticity to cost of a menu and forecasting in the case of the opening of new catering locations are presented in Section 4.4 and 4.5 . respectively. Elasticity to the cost of a menu increases with dynamic models with agent effect. In the scenario of the opening of a new catering location, predicted average number of visits correspond to point-of-sale data.

This model can be applied in pedestrian facilities to estimate demand for specific locations. Wooldridge's approach is easy to implement for discrete choice models with many alternatives and improves the estimation and predictive power of the model. Our model specification could be extended towards more complex discrete choice models (e.g., a nested 
logit where categories of catering locations would be the nests in our case study). Collection of more socioeconomic data would also improve the specification and prove useful for marketing purposes. On campuses, in transportation hubs or music festivals, information on congestion at location (i.e., queues for a service) is likely to be significant in explaining people's behavior. Endogeneity in the model due to congestion could also be corrected, using the occupation rates for each location as measures of queues and congestion at these locations. Some endogeneity could also be related to group effects, when a group chooses a location together instead of each individual independently (Louviere et al.; 2005, Section 2 ). This could be corrected using proximity as a measure of social networks. Finally, space syntax has been used in recent research and could help in formalizing intuitions such as "visibility" in public spaces.

\section{Acknowledgments}

This research is supported by the Swiss National Science Foundation Grant 200021-141099 "Pedestrian dynamics: flows and behavior". The authors would like to thank Etienne Marclay and Nils Rinaldi for providing the point-of-sale data. The authors would also like to thank the reviewers for their helpful comments and suggestions to improve this article.

\section{References}

Aarts, H. and Dijksterhuis, A. (2000). The automatic activation of goal-directed behavioour: The case of travel habits, Journal of Environmental Psychology 20(1): 75-82.

URL: $h t t p: / / d x . d o i . o r g / 10.1006 / j e v p .1999 .0156$

Akay, A. (2012). Finite-sample comparison of alternative methods for estimating dynamic panel data models, Journal of Applied Econometrics 27(7): 1189-1204.

URL: $h t t p: / / d x . d o i . o r g / 10.1002 / j a e .1254$

Arnold, S. J., Handelman, J. and Tigert, D. J. (1996). Organizational legitimacy and retail store patronage, Journal of Business Research 35(3): 229-239.

URL: http://dx.doi.org/10.1016/0148-2963(95)00128-X

Arnold, S. J., Oum, T. H. and Tigert, D. J. (1983). Determinant Attributes in Retail Patronage: Seasonal, Temporal, Regional, and International Comparisons, Journal of Marketing Research 20(2): 149.

URL: http://dx.doi.org/10.2307/3151681

Arulampalam, W. and Stewart, M. B. (2009). Simplified Implementation of the Heckman Estimator of the Dynamic Probit Model and a Comparison with Alternative Estimators, Oxford Bulletin of Economics and Statistics 71(5): 659-681.

URL: $h t t p: / / d x . d o i . o r g / 10.1111 / j .1468-0084.2009 .00554 . x$

Axhausen, K. W., Löchl, M., Schlich, R., Buhl, T. and Widmer, P. (2007). Fatigue in long-duration travel diaries, Transportation 34(2): 143-160.

URL: $h t t p: / / d x . d o i . o r g / 10.1007 / s 11116-006-9106-4$

Axhausen, K. W., Zimmermann, A., Schönfelder, S., Rindsfüser, G. and Haupt, T. (2002). Observing the rhythms of daily life: A six-week travel diary, Transportation 29(2): 95124.

URL: http://dx.doi.org/10.1023/A:1014247822322 
Bamberg, S., Ajzen, I. and Schmidt, P. (2003). Choice of Travel Mode in the Theory of Planned Behavior: The Roles of Past Behavior, Habit, and Reasoned Action, Basic and Applied Social Psychology 25(3): 175-187.

URL: http://dx.doi.org/10.1207/S15324834BASP2503_01

Bekhor, S., Cohen, Y. and Solomon, C. (2013). Evaluating long-distance travel patterns in Israel by tracking cellular phone positions, Journal of Advanced Transportation 47(4): 435-446.

URL: http://dx.doi.org/10.1002/atr.170

Ben-Akiva, M. and Lerman, S. R. (1985). Discrete Choice Analysis: Theory and Application to Travel Demand, MIT Press, Cambridge, MA.

Bhargava, A. and Sargan, J. D. (1983). Estimating Dynamic Random Effects Models from Panel Data Covering Short Time Periods, Econometrica 51(6): 1635.

URL: http://dx.doi.org/10.2307/1912110

Bierlaire, M. (2003). BIOGEME: a free package for the estimation of discrete choice models, Proceedings of the 3rd Swiss Transportation Research Conference, Monte Verità, Ascona, Switzerland.

URL: http://infoscience.epfl.ch/record/117133/files/bierlaire.pdf

Bierlaire, M. and Fetiarison, M. (2009). Estimation of discrete choice models: extending BIOGEME., Swiss Transport Research Conference (STRC), Monte Verità, Ascona, Switzerland.

URL: http://www.strc.ch/conferences/2009/Bierlaire_3.pdf

Bigano, A., Hamilton, J. M. and Tol, R. S. J. (2006). The Impact of Climate on Holiday Destination Choice, Climatic Change 76(3-4): 389-406.

URL: $h t t p: / / d x . d o i . o r g / 10.1007 / s 10584-005-9015-0$

Borgers, A. and Timmermans, H. (1986). A Model of Pedestrian Route Choice and Demand for Retail Facilities within Inner-City Shopping Areas, Geographical Analysis 18(2): 115128.

URL: $h t t p: / / d x . d o i . o r g / 10.1111 / j .1538-4632.1986 . t b 00086 . x$

Buisson, A. (2014). Individual activity-travel analysis based on smartphone WiFi data, Master thesis, EPFL.

URL: http://infoscience.epfl.ch/record/209106

Burton, S., Tangari, A. H., Howlett, E. and Turri, A. M. (2014). How the Perceived Healthfulness of Restaurant Menu Items Influences Sodium and Calorie Misperceptions: Implications for Nutrition Disclosures in Chain Restaurants, Journal of Consumer Affairs 48(1): 62-95.

URL: http://dx.doi.org/10.1111/joca.12015

Calabrese, F., Diao, M., Di Lorenzo, G., Ferreira, J. and Ratti, C. (2013). Understanding individual mobility patterns from urban sensing data: A mobile phone trace example, Transportation Research Part C 26(0): 301-313.

URL: $h$ ttp://dx.doi.org/10.1016/j.trc.2012.09.009

Cambridge Systematics Europe (1984). Estimation and Application of Disaggregate Models of Mode and Destination Choice, Technical report, Régie Autonome des Transports parisien, Paris. 
Carrel, A., Sengupta, R. and Walker, J. L. (2015). The San Francisco Travel Quality Study: Tracking Trials and Tribulations of a Transit Taker, Technical report, University of California, Berkeley, Berkeley, Ca.

URL: http://www.joanwalker.com/uploads/3/6/9/5/3695513/carrel_et_al_2015_sftqs_.pdf

Carrion, C., Pereira, F., Ball, R., Zhao, F., Kim, Y., Nawarathne, K., Zheng, N., Zegras, C. and Ben-Akiva, M. (2014). Evaluating FMS: A Preliminary Comparison with a Traditional Travel Survey, Transporation Research Board 93rd Annual Meeting, Washington D.C.

Chen, X. and Yang, X. (2014). Does food environment influence food choices? A geographical analysis through "tweets", Applied Geography 51: 82-89.

URL: http://dx.doi.org/10.1016/j.apgeog.2014.04.003

Chi, C. G.-Q. and Qu, H. (2008). Examining the structural relationships of destination image, tourist satisfaction and destination loyalty: An integrated approach, Tourism Management 29(4): 624-636.

URL: http://dx.doi.org/10.1016/j.tourman.2007.06.007

Cottrill, C., Pereira, F., Zhao, F., Dias, I., Lim, H., Ben-Akiva, M. and Zegras, P. (2013). Future Mobility Survey, Transportation Research Record: Journal of the Transportation Research Board 2354(07): 59-67.

URL: http://dx.doi.org/10.3141/2354-07

Danalet, A. (2015a). A Bayesian Approach to Detect Pedestrian Destination-Sequences from WiFi Signatures: Data (Transp. Res. Part C, 2014).

URL: $h t t p: / / d x$.doi.org/10.5281/zenodo.15798

Danalet, A. (2015b). Activity choice modeling for pedestrian facilities, PhD thesis, EPFL. URL: http://dx.doi.org/10.5075/epfl-thesis-6806

Danalet, A. and Bierlaire, M. (2015). Importance sampling for activity path choice, 15th Swiss Transport Research Conference (STRC), Monte Verità, Ascona, Switzerland.

Danalet, A., Farooq, B. and Bierlaire, M. (2014). A Bayesian approach to detect pedestrian destination-sequences from WiFi signatures, Transportation Research Part C 44: 146170 .

URL: http://dx.doi.org/10.1016/j.trc.2014.03.015

Deaton, A. (1985). Panel data from time series of cross-sections, Journal of Econometrics 30(1-2): 109-126.

URL: http://dx.doi.org/10.1016/0304-4076(85)90134-4

Dellaert, B. G. C., Arentze, T. A., Bierlaire, M., Borgers, A. W. J. and Timmermans, H. J. P. (1998). Investigating Consumers' Tendency to Combine Multiple Shopping Purposes and Destinations, Journal of Marketing Research 35(2): 177.

URL: http://dx.doi.org/10.2307/3151846

Eash, R. (1999). Destination and Mode Choice Models for Nonmotorized Travel, Transportation Research Record: Journal of the Transportation Research Board 1674: 1-8.

Eriksson, L., Garvill, J. and Nordlund, A. M. (2008). Interrupting habitual car use: The importance of car habit strength and moral motivation for personal car use reduction, Transportation Research Part F: Traffic Psychology and Behaviour 11(1): 10-23.

URL: http://dx.doi.org/10.1016/j.trf.200\%.05.004 
Ettema, D. (1996). Activity based Travel Demand Modelling, PhD thesis, Eindhoven Technical University, Holland.

Etter, V., Kafsi, M. and Kazemi, E. (2012). Been There, Done That: What Your Mobility Traces Reveal about Your Behavior, Nokia Mobile Data Challenge 2012 Workshop, June 18-19, Newcastle, UK, pp. 1-6.

Eymann, A. and Ronning, G. (1997). Microeconometric models of tourists' destination choice, Regional Science and Urban Economics 27(6): 735-761.

URL: http://dx.doi.org/10.1016/S0166-0462(97)00006-9

Fesenmaier, D. (1988). Integrating Activity Patterns into Destination Choice Models, Journal of Lesiure Research 20(3): 175-191.

Fotheringham, A. S. (1986). Modelling hierarchical destination choice, Environment and Planning A 18(3): 401-418.

URL: http://dx.doi.org/10.1068/a180401

Fox, E. J., Montgomery, A. L. and Lodish, L. M. (2004). Consumer Shopping and Spending across Retail Formats, The Journal of Business 77(S2): S25-S60.

URL: $h t t p: / / d x$.doi.org/10.1086/381518

Fox, J., Daly, A., Hess, S. and Miller, E. (2014). Temporal transferability of models of mode-destination choice for the Greater Toronto and Hamilton Area, Journal of Transport and Land Use $\mathbf{7}(2): 41$.

URL: $h t t p: / /$ dx.doi.org/10.5198/jtlu.v7i2. 701

Frejinger, E. and Bierlaire, M. (2007). Capturing correlation with subnetworks in route choice models, Transportation Research Part B 41(3): 363-378.

URL: $h t t p: / / d x . d o i . o r g / 10.1016 / j . t r b .2006 .06 .003$

Frignani, M. Z., Auld, J., Mohammadian, A. K., Williams, C. and Nelson, P. (2010). Urban Travel Route and Activity Choice Survey (UTRACS): An Internet-Based Prompted Recall Activity Travel Survey using GPS Data, Transportation Research Record: Journal of the Transportation Research Board 2183: 19-28.

Furuichi, M. and Koppelman, F. S. (1994). An analysis of air travelers' departure airport and destination choice behavior, Transportation research Part A 28(3): 187-195.

Gardner, B. (2009). Modelling motivation and habit in stable travel mode contexts, Transportation Research Part F: Traffic Psychology and Behaviour 12(1): 68-76.

URL: $h t t p: / / d x . d o i . o r g / 10.1016 / j . t r f .2008 .08 .001$

Gärling, T. and Axhausen, K. W. (2003). Introduction: Habitual travel choice, Transportation 30(1): 1-11.

URL: http://dx.doi.org/10.1023/A:1021230223001

Golob, T. F., Kitamura, R. and Long, L. (eds) (1997). Panels for Transportation Planning, Transportation Research, Economics and Policy, Springer US, Boston, MA.

URL: $h t t p: / / d x$.doi.org/10.1007/978-1-4757-2642-8

Gössling, S., Scott, D., Hall, C. M., Ceron, J.-P. and Dubois, G. (2012). Consumer behaviour and demand response of tourists to climate change, Annals of Tourism Research 39(1): $36-58$.

URL: http://dx.doi.org/10.1016/j.annals.2011.11.002 
Grigolon, A. B., Borgers, A. W., Kemperman, A. D. and Timmermans, H. J. (2014). Vacation length choice: A dynamic mixed multinomial logit model, Tourism Management 41: 158-167.

URL: http://dx.doi.org/10.1016/j.tourman.2013.09.002

He, F., Wu, D., Yin, Y. and Guan, Y. (2013). Optimal deployment of public charging stations for plug-in hybrid electric vehicles, Transportation Research Part B: Methodological 47: 87-101.

URL: http://dx.doi.org/10.1016/j.trb.2012.09.007

Heckman, J. (1978). Dummy endogenous variables in a simultaneous equation system, Econometrica 46(4): 931-959.

URL: http://dx.doi.org/10.2307/1909757

Heckman, J. (1981). The incidental parameters problem and the problem of initial condition in estimating a discrete time-discrete data stochastic process, in C. Manski and D. McFadden (eds), Structural Analysis of Discrete Data with Econometric Applications, MIT Press, Cambridge, MA, pp. 179-185.

Hoogendoorn, S. P. and Bovy, P. H. L. (2004). Pedestrian route-choice and activity scheduling theory and models, Transportation Research Part B 38(2): 169-190.

URL: http://dx.doi.org/10.1016/S0191-2615(03)00007-9

Hsiao, C. (2003). Analysis of Panel Data, Cambridge University Press, Cambridge, UK.

Jong, G. D., Fox, J., Daly, A., Pieters, M. and Smit, R. (2004). Comparison of car ownership models, Transport Reviews 24(4): 379-408.

URL: http://dx.doi.org/10.1080/0144164032000138733

Kalakou, S., Bierlaire, M. and Moura, F. (2014). Effects of terminal planning on passenger choices, 14th Swiss Transport Research Conference (STRC), Monte Verità, Ascona, Switzerland.

URL: http://www.strc.ch/conferences/2014/Kalakou_Moura.pdf

Kazagli, E., Chen, J. and Bierlaire, M. (2014). Individual Mobility Analysis Using Smartphone Data, in S. Rasouli and H. Timmermans (eds), Mobile Technologies for ActivityTravel Data Collection and Analysis, IGI Global, chapter 12, pp. 187-208.

URL: http://dx.doi.org/10.4018/978-1-4666-6170-7.ch012

Kitamura, R. (1990). Panel analysis in transportation planning: An overview, Transportation Research Part A: General 24(6): 401-415.

URL: http://dx.doi.org/10.1016/0191-2607(90)90032-2

Louviere, J., Train, K., Ben-Akiva, M., Bhat, C., Brownstone, D., Cameron, T. A., Carson, R. T., Deshazo, J. R., Fiebig, D., Greene, W., Hensher, D. and Waldman, D. (2005). Recent Progress on Endogeneity in Choice Modeling, Marketing Letters 16(3-4): 255265.

URL: $h t t p: / / d x d . o i . o r g / 10.1007 / s 11002-005-5890-4$

McDonald, N. (2015). Assessing the Travel of the Millennial Generation Using PseudoPanels, 14th International Conference on Travel Behaviour Research (IATBR), Windsor.

McFadden, D. (2001). Economic Choices, The American Economic Review 91(3): 351-378. URL: http://www.jstor.org/stable/2677869 
Miller, H. J. (2014). Activity-Based Analysis, in M. M. Fischer and P. Nijkamp (eds), Handbook of Regional Science, Springer Berlin Heidelberg, Berlin, Heidelberg, pp. 705724.

URL: $h t t p: / / d x . d o i . o r g / 10.1007 / 978-3-642-23430-9 \_106$

O'Connor, A., Zerger, A. and Itami, B. (2005). Geo-temporal tracking and analysis of tourist movement, Mathematics and Computers in Simulation 69(1-2): 135-150.

URL: http://dx.doi.org/10.1016/j.matcom.2005.02.036

Oppermann, M. (2000). Tourism Destination Loyalty, Journal of Travel Research 39(1): $78-84$.

URL: http://dx.doi.org/10.1177/004728750003900110

Ortúzar, J. D. D., Armoogum, J., Madre, J. and Potier, F. (2011). Continuous Mobility Surveys: The State of Practice, Transport Reviews 31(3): 293-312.

URL: http://dx.doi.org/10.1080/01441647.2010.510224

Rabe-Hesketh, S. and Skrondal, A. (2013). Avoiding biased versions of Wooldridge's simple solution to the initial conditions problem, Economics Letters 120(2): 346-349.

URL: $h t t p: / / d x$. doi.org/10.1016/j.econlet.2013.05.009

Rindfüser, G., Mühlhans, H., Doherty, S. T. and Beackmann, K. J. (2003). Tracing the planning and execution of activities and their attributes: Design and application of a hand-held scheduling process survey, 10th International Conference on Travel Behaviour Research, August 10-14, Lucerne, Switzerland, pp. 1-31.

Robin, T. and Bierlaire, M. (2012). Modeling investor behavior, Journal of Choice Modelling 5(2): 98-130.

URL: $h t t p: / / d x . d o i . o r g / 10.1016 / S 1755-5345(13) 70054-X$

Scarpa, R. and Thiene, M. (2005). Destination Choice Models for Rock Climbing in the North eastern Alps: A Latent-Class Approach Based on Intensity of Preferences, Land Economics 81(3): 426-444.

Schlich, R. (2004). Verhaltenshomogene Gruppen in Längsschnitterhebungen, PhD thesis, ETH Zurich.

Schwanen, T., Banister, D. and Anable, J. (2012). Rethinking habits and their role in behaviour change: the case of low-carbon mobility, Journal of Transport Geography 24: 522-532.

URL: http://dx.doi.org/10.1016/j.jtrangeo.2012.06.003

Scott, D. M. and He, S. Y. (2012). Modeling constrained destination choice for shopping: a GIS-based, time-geographic approach, Journal of Transport Geography 23: 60-71.

URL: http://dx.doi.org/10.1016/j.jtrangeo.2012.03.021

Seddighi, H. and Theocharous, A. (2002). A model of tourism destination choice: a theoretical and empirical analysis, Tourism Management 23(5): 475-487.

URL: http://dx.doi.org/10.1016/S0261-5177(02)00012-2

Shobeirinejad, M., Veitch, T., Smart, J. C. R., Sipe, N. and Burke, M. (2013). Destination choice decisions of retail travellers: results from discrete choice modelling in Brisbane, Australasian Transport Research Forum (ATRF), Brisbane, Queensland, Australia. 
Sivakumar, A. and Bhat, C. (2007). Comprehensive, Unified Framework for Analyzing Spatial Location Choice, Transportation Research Record: Journal of the Transportation Research Board 2003: 103-111.

URL: http://dx.doi.org/10.3141/2003-13

Stopher, P. R. and Greaves, S. P. (2007). Household travel surveys: Where are we going?, Transportation Research Part A 41(5): 367-381.

URL: http://dx.doi.org/10.1016/j.tra.2006.09.005

Thiene, M. and Scarpa, R. (2009). Deriving and Testing Efficient Estimates of WTP Distributions in Destination Choice Models, Environmental and Resource Economics 44(3): 379-395.

URL: dx.doi.org/10.1007/s10640-009-9291-7

Thøgersen, J. (2006). Understanding repetitive travel mode choices in a stable context: A panel study approach, Transportation Research Part A: Policy and Practice 40(8): 621638.

URL: http://dx.doi.org/10.1016/j.tra.2005.11.004

Timmermans, H. J. P. (1996). A stated choice model of sequential mode and destination choice behaviour for shopping trips, Environment and Planning A 28(1): 173-184.

URL: http://dx.doi.org/10.1068/a280173

Timmermans, H., van der Hagen, X. and Borgers, A. (1992). Transportation systems, retail environments and pedestrian trip chaining behaviour: Modelling issues and applications, Transportation Research Part B: Methodological 26(1): 45-59.

URL: http://dx.doi.org/10.1016/0191-2615(92)90019-S

Tinguely, L. (2015). Exploiting pedestrian WiFi traces for destination choice modeling, Master thesis, EPFL.

URL: http://infoscience.epfl.ch/record/209732

Ton, D. (2014). NAVISTATION: a study into the route and activity location choice behaviour of departing pedestrians in train stations, Master thesis, Delft University of Technology.

Train, K. (2003). Discrete Choice Methods with Simulation, Cambridge University Press, University of California, Berkeley.

Um, S. and Crompton, J. L. (1990). Attitude determinants in tourism destination choice, Annals of Tourism Research 17(3): 432-448.

URL: http://dx.doi.org/10.1016/0160-7383(90)90008-F

Verplanken, B., Walker, I., Davis, A. and Jurasek, M. (2008). Context change and travel mode choice: Combining the habit discontinuity and self-activation hypotheses, Journal of Environmental Psychology 28(2): 121-127.

URL: http://dx.doi.org/10.1016/j.jenvp.2007.10.005

Weis, C. and Axhausen, K. W. (2009). Induced travel demand: Evidence from a pseudo panel data based structural equations model, Research in Transportation Economics 25(1): 8-18.

URL: $h t t p: / / d x . d o i . o r g / 10.1016 /$ j.retrec.2009.08.007 
Whynes, D. K., Reedand, G. and Newbold, P. (1996). General Practitioners' Choice of Referral Destination: A Probit Analysis, Managerial and Decision Economics 17(6): 587.

Woodside, A. G. and Lysonski, S. (1989). A General Model Of Traveler Destination Choice, Journal of Travel Research 27(4): 8-14.

URL: http://dx.doi.org/10.1177/004728758902700402

Wooldridge, J. M. (2005). Simple solutions to the initial conditions problem in dynamic, nonlinear panel data models with unobserved heterogeneity, Journal of Applied Econometrics 20(1): 39-54.

URL: http://dx.doi.org/10.1002/jae.770

Wu, L. (2012). A Tourist Behavior Model System With Multi-Faceted Dependencies and Interactions, $\mathrm{PhD}$ thesis, Hiroshima University.

Yang, D. and Timmermans, H. (2015). Analysis of consumer response to fuel price fluctuations applying sample selection model to GPS panel data: Dynamics in individualsâĂŹ car use, Transportation Research Part D: Transport and Environment 38: 67-79.

URL: http://dx.doi.org/10.1016/j.trd.2015.04.011

Yang, Y., Fik, T. and Zhang, J. (2013). Modeling sequential tourist flows: Where is the next destination?, Annals of Tourism Research 43: 297-320.

URL: http://dx.doi.org/10.1016/j.annals.2013.07.005

Yoshimura, Y., Sobolevsky, S., Ratti, C., Girardin, F., Carrascal, J. P., Blat, J. and Sinatra, R. (2014). An analysis of visitors' behavior in The Louvre Museum: a study using Bluetooth data, Environment and Planning B: Planning and Design 41(6): 11131131.

URL: $h t t p: / / d x . d o i . o r g / 10.1068 / b 130047 p$

Zhu, W. and Timmermans, H. (2011). Modeling pedestrian shopping behavior using principles of bounded rationality: model comparison and validation, Journal of Geographical Systems 13(2): 101-126.

URL: http://dx.doi.org/10.1007/s10109-010-0122-8

Zhu, W., Timmermans, H. and Wang, D. (2006). Temporal Variation in Consumer Spatial Behavior in Shopping Streets, Journal of Urban Planning and Development 132(3): 166171.

URL: http://dx.doi.org/10.1061/(ASCE)0733-9488(2006)132:3(166)

\section{A Appendix}

\section{A.1 Descriptive statistics of the WiFi traces}

As described in Danalet et al. (2014), WiFi traces have been anonymized but the category of people has been collected. Table 5 shows the number of daily observations and the total number of individuals observed per category. Employees are overrepresented in the sample.

The number of times each catering location is chosen is described in Table 6. The most visited catering location is L'Esplanade, very central on the campus. Le Parmentier and Le Vinci are very close and share the same kitchen; their counts of being chosen from WiFi traces are biased towards Le Parmentier, with a larger capacity and therefore a larger attractivity (see Danalet et al.; 2014). Number of visits in catering locations in the Rolex 


\begin{tabular}{lcrr}
\hline Category & $\begin{array}{c}\text { Number of } \\
\text { observations }\end{array}$ & $\begin{array}{r}\text { Number of } \\
\text { individuals }\end{array}$ \\
\hline Employees & 1219 & \multicolumn{2}{c}{145} \\
Students, among which.. & 649 & 66 & \\
$\quad$ Civil engineering, Bachelor, 4th semester & & 131 & 12 \\
Computer science, Bachelor, 4th semester & 87 & 6 \\
Computer science, Master, 2nd semester & 53 & 6 \\
$\quad$ Mathematics, Bachelor, 2nd semester & 108 & 13 \\
Life science and technology, Bachelor, 2nd semester & & 138 & 11 \\
$\quad$ Physics, Bachelor, 2nd semester & 1868 & & 211 \\
\hline Total & & & \\
\hline
\end{tabular}

Table 5: Number of observations and of individuals per categories of individuals.

Learning Center (RLC), Le Hodler and Le Klee, are most probably underestimated due to the large attractivity of the library (see again Danalet et al.; 2014).

\begin{tabular}{lrrr|r}
\hline & \multicolumn{3}{c}{ Count of chosen alternatives } \\
Catering locations & Morning & Lunch & After lunch & Total \\
\hline Cafeteria Cafe Le Klee & 1 & 1 & 2 & 4 \\
Self-service BC & 46 & 60 & 40 & 146 \\
Other BM & 11 & 13 & 22 & 46 \\
Cafeteria ELA & 38 & 38 & 49 & 125 \\
Cafeteria INM & 3 & 3 & 7 & 13 \\
Cafeteria MX & 39 & 15 & 30 & 84 \\
Other PH & 38 & 7 & 34 & 79 \\
Cafeteria L'Arcadie & 19 & 11 & 8 & 38 \\
Self-service L'Atlantide & 73 & 11 & 51 & 135 \\
Restaurant Le Copernic & 0 & 6 & 0 & 6 \\
Self-service Le Corbusier & 17 & 56 & 0 & 73 \\
Cafeteria Le Giacometti & 47 & 44 & 85 & 176 \\
Self-service Le Parmentier & 14 & 68 & 53 & 135 \\
Self-service Le Vinci & 1 & 1 & 0 & 2 \\
Self-service L'Esplanade & 104 & 102 & 206 & 412 \\
Self-service L'Ornithorynque & 30 & 69 & 0 & 99 \\
Caravan Pizza & 18 & 24 & 22 & 64 \\
Caravan Kebab & 13 & 11 & 30 & 54 \\
Cafeteria Satellite & 37 & 11 & 87 & 135 \\
Self-service Le Hodler & 13 & 22 & 0 & 35 \\
Restaurant Table de Vallotton & 0 & 7 & 0 & 7 \\
\hline Total & 562 & 580 & 728 & 1868 \\
\hline
\end{tabular}

Table 6: Number of times each catering location is chosen in the dataset. Morning represents visits starting before 11:30, Lunch visits starting between 11:30 and 14:00, and After lunch visits starting after 14:00.

The distance walked to reach a catering location (Fig. 4) is computed used a weighted 
shortest path (Danalet et al. 2014). It takes into account the pedestrian network and the different floors on the campus. In 478 cases, distance could not be computed (previous location to the catering destination is not properly connected to the network).

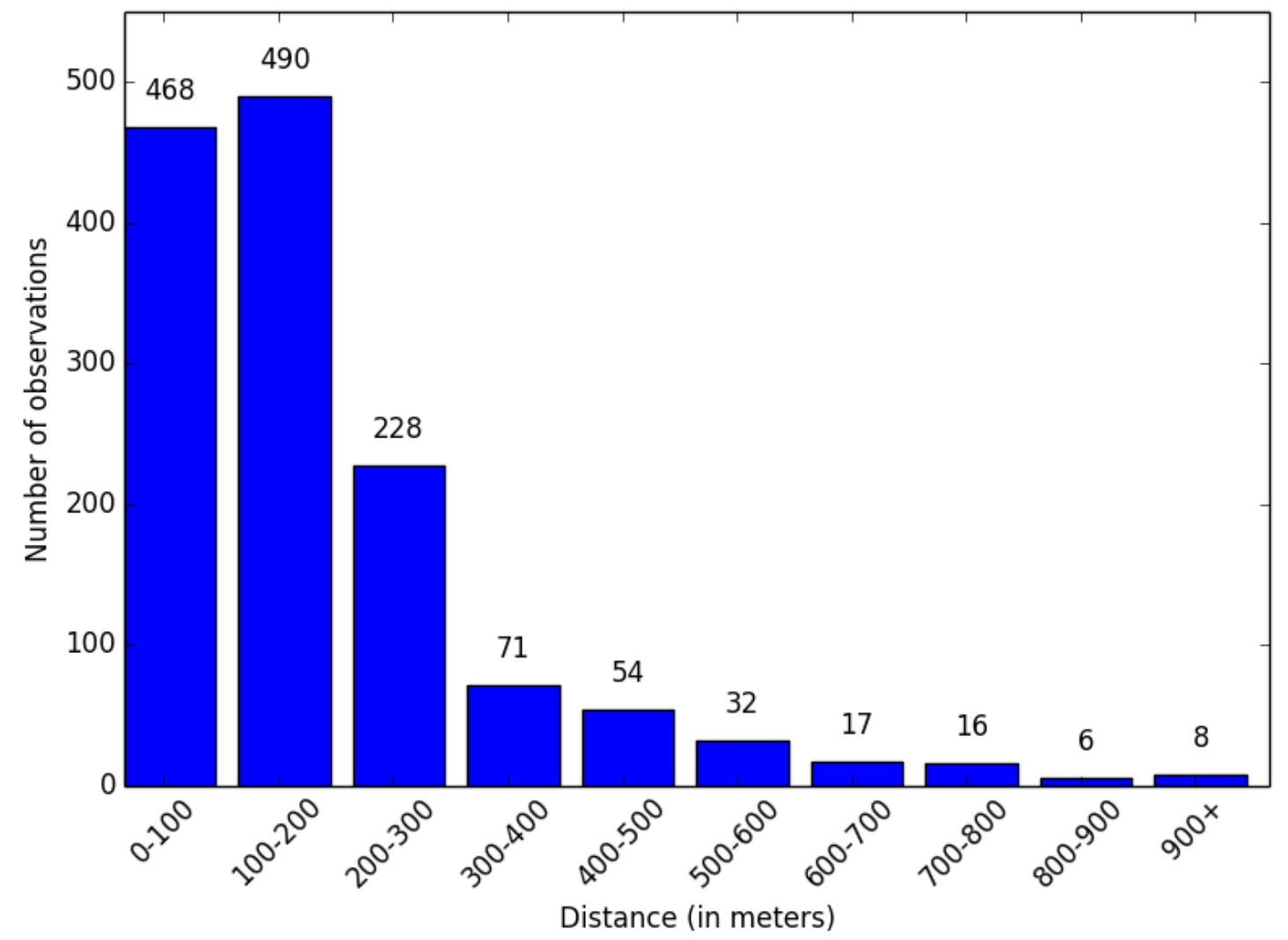

Figure 4: Distance walked to reach a catering location, in meters.

More descriptive statistics about the data used in this case study are available in Tinguely (2015). 


\section{A.2 Estimation results for the 4 models of Table 2}

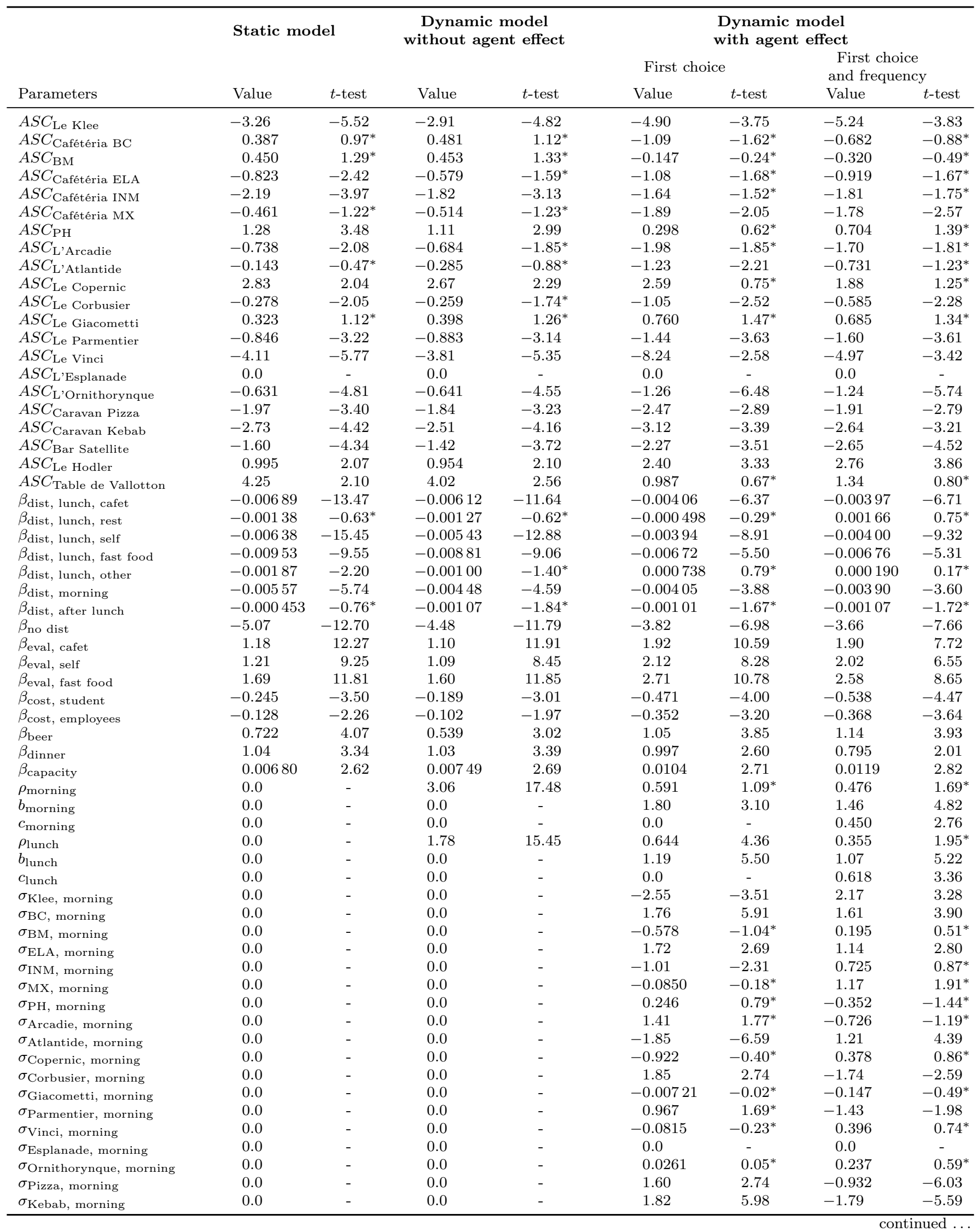




\begin{tabular}{|c|c|c|c|c|c|c|c|c|}
\hline \multirow[b]{3}{*}{ Parameters } & \multirow{2}{*}{\multicolumn{2}{|c|}{ Static model }} & \multirow{2}{*}{\multicolumn{2}{|c|}{$\begin{array}{c}\text { Dynamic model } \\
\text { without agent effect }\end{array}$}} & \multicolumn{4}{|c|}{$\begin{array}{l}\text { Dynamic model } \\
\text { with agent effect }\end{array}$} \\
\hline & & & & & \multicolumn{2}{|c|}{ First choice } & \multicolumn{2}{|c|}{$\begin{array}{c}\text { First choice } \\
\text { and frequency }\end{array}$} \\
\hline & Value & $t$-test & Value & $t$-test & Value & $t$-test & Value & $t$-test \\
\hline$\sigma_{\text {Satellite, }}$ morning & 0.0 & - & 0.0 & - & 2.02 & 5.35 & -2.32 & -6.41 \\
\hline$\sigma_{\text {Hodler, morning }}$ & 0.0 & - & 0.0 & - & 1.71 & 2.42 & 0.290 & $0.41^{*}$ \\
\hline$\sigma_{\text {Vallotton, morning }}$ & 0.0 & - & 0.0 & - & 0.578 & $0.53^{*}$ & 0.292 & $0.75^{*}$ \\
\hline$\sigma_{\text {Klee, lunch }}$ & 0.0 & - & 0.0 & - & -2.59 & -5.44 & 2.71 & 7.08 \\
\hline$\sigma_{\mathrm{BC}, \text { lunch }}$ & 0.0 & - & 0.0 & - & 2.06 & 6.11 & -2.20 & -7.48 \\
\hline$\sigma_{\mathrm{BM}}$, lunch & 0.0 & - & 0.0 & - & 2.33 & 3.52 & -2.50 & -4.18 \\
\hline$\sigma_{\mathrm{ELA}}$, lunch & 0.0 & - & 0.0 & - & -1.05 & -3.92 & -0.789 & -2.60 \\
\hline$\sigma_{\text {INM, lunch }}$ & 0.0 & - & 0.0 & - & 0.883 & $1.47^{*}$ & -1.33 & -2.83 \\
\hline$\sigma_{\mathrm{MX}}$, lunch & 0.0 & - & 0.0 & - & -2.06 & -6.27 & 1.66 & 9.55 \\
\hline$\sigma_{\mathrm{PH}, \text { lunch }}$ & 0.0 & - & 0.0 & - & 2.63 & 7.13 & -2.30 & -3.39 \\
\hline$\sigma_{\text {Arcadie, lunch }}$ & 0.0 & - & 0.0 & - & 2.97 & 5.74 & 2.46 & 5.25 \\
\hline$\sigma_{\text {Atlantide, lunch }}$ & 0.0 & - & 0.0 & - & 1.85 & 5.44 & -1.54 & -6.82 \\
\hline$\sigma_{\text {Copernic, }}$ lunch & 0.0 & - & 0.0 & - & 5.78 & 2.92 & 6.06 & 4.32 \\
\hline$\sigma_{\text {Corbusier, lunch }}$ & 0.0 & - & 0.0 & - & -1.27 & -3.89 & -0.855 & -3.16 \\
\hline$\sigma_{\text {Giacometti, lunch }}$ & 0.0 & - & 0.0 & - & -1.31 & -6.13 & 1.24 & 6.35 \\
\hline$\sigma_{\text {Parmentier, lunch }}$ & 0.0 & - & 0.0 & - & 0.961 & 3.75 & -1.19 & -2.57 \\
\hline$\sigma_{\text {Vinci, lunch }}$ & 0.0 & - & 0.0 & - & 3.56 & $1.91^{*}$ & -1.37 & -1.36 \\
\hline$\sigma_{\text {Esplanade, }}$ lunch & 0.0 & - & 0.0 & - & 0.0 & - & 0.0 & - \\
\hline$\sigma_{\text {Ornithorynque, lunch }}$ & 0.0 & - & 0.0 & - & 0.128 & $0.49^{*}$ & -0.258 & $-1.23^{*}$ \\
\hline$\sigma_{\text {Pizza, lunch }}$ & 0.0 & - & 0.0 & - & -1.24 & -5.42 & 1.29 & 5.15 \\
\hline$\sigma_{\text {Kebab, lunch }}$ & 0.0 & - & 0.0 & - & 0.677 & 3.00 & -1.11 & -4.48 \\
\hline$\sigma_{\text {Satellite, lunch }}$ & 0.0 & - & 0.0 & - & 0.776 & 5.26 & -1.20 & -4.13 \\
\hline$\sigma_{\text {Hodler, lunch }}$ & 0.0 & - & 0.0 & - & 1.05 & 3.51 & -0.910 & $-1.91^{*}$ \\
\hline$\sigma_{\text {Vallotton, lunch }}$ & 0.0 & - & 0.0 & - & 10.7 & 5.52 & -10.8 & -7.20 \\
\hline $\mathrm{Nb}$ of observations & \multicolumn{8}{|c|}{1868} \\
\hline $\mathcal{L}(0)$ & \\
\hline $\mathrm{Nb}$ estim. param. & \multicolumn{2}{|l|}{36} & \multicolumn{2}{|c|}{38} & \multicolumn{2}{|c|}{80} & \multicolumn{2}{|c|}{82} \\
\hline $\mathcal{L}(\hat{\beta})$ & \multicolumn{2}{|l|}{-3446.109} & \multicolumn{2}{|c|}{-3092.106} & \multicolumn{2}{|c|}{-2631.929} & \multicolumn{2}{|c|}{-2623.843} \\
\hline Adjused rho square $\bar{\rho}^{2}$ & \multirow[t]{2}{*}{0.309} & & \multicolumn{2}{|c|}{0.379} & 0.4 & & \multicolumn{2}{|c|}{0.480} \\
\hline Likelihood ratio test & & \multicolumn{2}{|c|}{$354.003(>5.99)$} & 920. & $58.12)$ & \multicolumn{3}{|c|}{$16.172(>5.99)$} \\
\hline
\end{tabular}

Table 7: Summary of estimation results for the 4 models of Table 2 1868 observations are used for estimation. Parameters without stars are significantly different from zero with a $95 \%$ confidence level. A likelihood ratio test is performed between the static model and the dynamic model without agent effect, between the dynamic model without agent effect and the dynamic model with agent effect (first choice specification), and between the dynamic model with agent effect (first choice specification) and the dynamic model with agent effect (first choice and frequency). The numbers in parenthesis for the likelihood ratio tests are the percentiles of the $\chi^{2}$ distribution. 


\section{A.3 Elasticity of choice probabilities to price: detailed results}

\begin{tabular}{|c|c|c|c|c|c|}
\hline \multirow[b]{2}{*}{ Catering locations } & & \multirow[t]{2}{*}{ Static model } & \multirow[t]{2}{*}{$\begin{array}{c}\text { Dynamic model } \\
\text { without agent effect }\end{array}$} & \multicolumn{2}{|c|}{$\begin{array}{l}\text { Dynamic model with } \\
\text { agent effect correction }\end{array}$} \\
\hline & & & & First choice & $\begin{array}{l}\text { First choice } \\
\text { and frequency }\end{array}$ \\
\hline \multirow{2}{*}{ L'Arcadie } & Employees & -1.23989 & -0.985452 & -3.39526 & -3.57178 \\
\hline & Students & -2.38484 & -1.83835 & -4.57827 & -4.75158 \\
\hline \multirow{2}{*}{ L'Atlantide } & Employees & -1.13413 & -0.895157 & -3.18069 & -3.32638 \\
\hline & Students & -2.27122 & -1.77387 & -4.44407 & -4.625 \\
\hline \multirow{2}{*}{$\mathrm{BC}$} & Employees & -0.936438 & -0.739586 & -2.61785 & -2.7033 \\
\hline & Students & -1.57302 & -1.2261 & -3.08235 & -3.15199 \\
\hline \multirow{2}{*}{ Le Copernic } & Employees & -2.35353 & -1.87112 & -6.41268 & -6.68158 \\
\hline & Students & -4.51551 & -3.47645 & -8.64327 & -8.90621 \\
\hline \multirow{2}{*}{ Le Corbusier } & Employees & -0.929999 & -0.735688 & -2.61505 & -2.70122 \\
\hline & Students & -1.54962 & -1.20379 & -2.97714 & -3.07526 \\
\hline \multirow{2}{*}{ ELA } & Employees & -0.684047 & -0.547564 & -1.87449 & -1.9601 \\
\hline & Students & -1.27976 & -0.972102 & -2.4586 & -2.52925 \\
\hline \multirow{2}{*}{ L'Esplanade } & Employees & -0.815134 & -0.656035 & -2.19422 & -2.36297 \\
\hline & Students & -1.27379 & -0.959653 & -2.35676 & -2.441 \\
\hline \multirow{2}{*}{ Le Giacometti } & Employees & -0.693894 & -0.553458 & -1.8864 & -1.96811 \\
\hline & Students & -1.31332 & -1.00551 & -2.49273 & -2.58709 \\
\hline \multirow{2}{*}{ Le Hodler } & Employees & -1.7247 & -1.37671 & -4.73638 & -4.96936 \\
\hline & Students & -3.24068 & -2.47713 & -6.3035 & -6.46166 \\
\hline \multirow{2}{*}{ INM } & Employees & -0.763795 & -0.607341 & -2.08843 & -2.17938 \\
\hline & Students & -1.45722 & -1.1218 & -2.79651 & -2.87987 \\
\hline \multirow{2}{*}{ Kebab } & Employees & -0.864627 & -0.689636 & -2.37133 & -2.46379 \\
\hline & Students & -1.6376 & -1.25415 & -3.1567 & -3.2466 \\
\hline \multirow{2}{*}{ Le Klee } & Employees & -0.794574 & -0.631613 & -2.17519 & -2.27434 \\
\hline & Students & -1.51289 & -1.16528 & -2.91007 & -3.00368 \\
\hline \multirow{2}{*}{ MX } & Employees & -0.971626 & -0.767171 & -2.70928 & -2.8277 \\
\hline & Students & -1.62567 & -1.26778 & -3.19163 & -3.31779 \\
\hline \multirow{2}{*}{ Ornithorynque } & Employees & -0.84435 & -0.664995 & -2.24917 & -2.37491 \\
\hline & Students & -1.67028 & -1.30676 & -3.25905 & -3.3904 \\
\hline \multirow{2}{*}{ Le Parmentier } & Employees & -0.871571 & -0.695141 & -2.37836 & -2.49491 \\
\hline & Students & -1.47515 & -1.12795 & -2.73667 & -2.8268 \\
\hline \multirow{2}{*}{ Pizza } & Employees & -0.977648 & -0.777131 & -2.66259 & -2.79363 \\
\hline & Students & -1.8736 & -1.44253 & -3.58497 & -3.72084 \\
\hline \multirow{2}{*}{ Sat } & Employees & -0.596256 & -0.474232 & -1.63987 & -1.69052 \\
\hline & Students & -1.12653 & -0.866874 & -2.1905 & -2.22546 \\
\hline \multirow{2}{*}{ Table de Vallotton } & Employees & -3.9529 & -3.14098 & -10.5511 & -10.9123 \\
\hline & Students & -7.58275 & -5.83644 & -14.3337 & -14.7175 \\
\hline \multirow{2}{*}{ Le Vinci } & Employees & -1.02426 & -0.81411 & -2.80212 & -2.93623 \\
\hline & Students & -1.70861 & -1.31617 & -3.21097 & -3.33883 \\
\hline
\end{tabular}

Table 8: Average sample elasticities of choice probabilities to price 